\title{
La deriva interpretativa de los límites al crecimiento urbanístico del Plan de Ordenación del Territorio de Andalucía: un relato contradictorio.
}

\begin{abstract}
Pedro Górgolas Martín
Arquitecto. Máster en proyectos arquitectónicos.

Doctor por la Universidad de Sevilla.

Profesor del Departamento de Urbanística y Ordenación del Territorio de la Universidad de Sevilla. Redactor de planificación territorial y planeamiento urbanístico en la empresa consultora Territorio y Ciudad SLP.

SUMARIO.

I. INTRODUGGIÓN. EL URBANISMO ANDALUZ EN LOS AÑOS DEL CAMBIO DE MILENIO: ENTRE EL DESCONGIERTO Y LA PARÁLISIS. II. LA INSTRUCGIÓN 1/2007: FIJAGIÓN DE GRITERIOS PARA VALORAR LA ADEGUAGIÓN DEL PLANEAMIENTO GENERAL A LA NORMA 45 DEL POTA. 1. Los criterios de la Instrucción 1/2007 para determinar la superficie computable de crecimiento urbanístico y evaluar su adecuación a la Norma 45.4.a del POTA. 2. Los criterios establecidos en la Instrucción 1/2007 para el cómputo del crecimiento poblacional. III. LA ALTERACIÓN DE LOS CRITERIOS DE LA INSTRUGGIÓN 1/2007 DURANTE SU VIGENGIA: LOS INFORMES DE INGIDENGIA TERRITORIAL. IV.LA INSTRUGGIÓN 1/2012: ADEGUACIÓN A LA LEY 2/2012, DE 30 DE ENERO, DE MODIFICACIÓN DE LA LEY 7/2002, DE 17 DE DICIEMBRE, DE ORDENACIÓN URBANÍSTICA DE ANDALUGÍA. V.LA INSTRUCGIÓN 1/2013: EL URBANISMO ANDALUZ PAREGE ENCAMINARSE POR LA SENDA DE LA SOSTENIBILIDAD. 1. La reinterpretación de los criterios aplicables para evaluar la adecuación del planeamiento general a la Norma 45 del POTA. 2. La incidencia del Decreto-Ley 5/2012 en la capacidad del planeamiento general para promover nuevos crecimientos urbanísticos.VI. LA INVOLUGIÓN CAUSADA POR LA INSTRUGCIÓN 1/2014: LA IRRUPGIÓN TRIUNFANTE DE LA HERENGIA URBANÍSTICA RECIBIDA. 1. Griterios para comprobar la adecuación del PGOU a la planificación territorial. 2. Criterios para evaluar el cómputo del crecimiento urbanístico propuesto en innovaciones del PGOU. VII. CONGLUSIONES.
\end{abstract}


RESUMEN. La irrupción del Plan de Ordenación del Territorio de Andalucía supuso una importante convulsión en el urbanismo andaluz ${ }^{1}$. La regulación del modelo de ciudad compacta preceptuado en su Norma 45 y, específicamente, la imposición de límites a la capacidad decisoria de los ayuntamientos para promover crecimientos urbanísticos, impactó en una situación caracterizada por la vigencia de modelos territoriales que presentaban signos evidentes de sobreclasificación del suelo. Esta casuística fundamentó la necesidad, por parte de la Administración Autonómica, de fijar criterios y reglas para evaluar la adecuación a la planificación territorial de las innovaciones -revisiones integrales, revisiones parciales, modificaciones puntuales o planes de sectorización- a proponer en los Planes Generales de Ordenación Urbanística. Esta iniciativa se instrumentó mediante la formulación de Instrucciones administrativas -instrumentos sin fuerza normativa- lo cual resultó, cuanto menos, paradójico. Se formularon, en apenas siete años -los que median entre 2007 y 2014-, un total de cuatro Instrucciones, cuyo contenido denota una deriva interpretativa, en cierto modo incomprensible, sobre las actuaciones urbanísticas integrantes del crecimiento que habría que considerar computable a efectos de verificar el cumplimiento de los límites impuestos por la citada disposición. El análisis realizado en el artículo certificará el carácter errático, cambiante, voluble e impredecible de la política territorial desarrollada en la región andaluza en dicho periodo.

PALABRAS CLAVE: Modelo de ciudad compacta, límites al crecimiento, Instrucciones, política territorial.

ABSTRACT. The irruption of the Spatial Planning Plan of Andalusia was a major upheaval in andalusian urban planning. The regulation of the compact city model prescribed in its Rule 45 and, specifically, the imposition of limits on the decision-making capacity of city councils to promote urban growth, impacted on a situation characterized by the validity of territorial models that showed evident signs of overclassification of land. This casuistry based the need for the Regional Administration to establish criteria and rules to evaluate the suitability of the innovations for territorial planning - comprehensive revisions, partial revisions, specific modifications or sectorization plans - to be proposed in the General Urban Planning Plans. This initiative was implemented through the formulation of Administrative Instructions -instruments without normative force- which was paradoxical, to say the least. In just seven years - between 2007 and 2014 - a total of four Instructions were formulated, the content of which shows a somewhat incomprehensible interpretation of the urban development actions that form part of the growth that should be considered computable in order to verify compliance with the limits imposed by the

1 SÁNCHEZ GONZÁLEZ, J. F., "La consideración de las limitaciones al crecimiento como parámetro de sostenibilidad del medio ambiente urbano", en Administración de Andalucía. Revista Andaluza de Administración Pública, núm. 81 (2011), pp. 13-46. 
aforementioned provision. The analysis carried out in the article will certify the erratic, changing, volatile and unpredictable nature of the territorial policy developed in the Andalusian region during this period.

KEYWORDS: Compact city model, limits to growth, Instructions, territorial policy.

\section{INTRODUCGIÓN. EL URBANISMO ANDALUZ EN LOS AÑOS DEL GAMBIO DE MILENIO: ENTRE EL DESGONCIERTO Y LA PARÁLISIS.}

Habitualmente, la formulación de un nuevo Plan General de Ordenación Urbanística (PGOU) se produce sin haber agotado la máxima capacidad residencial prevista en el conjunto de actuaciones contempladas -en el documento objeto de revisión- en el suelo urbano no consolidado y el suelo urbanizable ${ }^{2}$. Por este motivo, el debate sobre el tratamiento que estas actuaciones deberían tener, a efectos del cumplimiento de los límites al crecimiento impuestos en el Plan de Ordenación del Territorio de Andalucía (POTA) ${ }^{3}$, alcanzó un protagonismo e intensidad notables ya que, en función de la capacidad residencial aún restante en el PGOU objeto de revisión, podría darse el caso que ésta, incluso, superase el máximo incremento poblacional admitido ${ }^{4}$, lo cual debería conducir a plantear «decrecimientos residenciales» en su revisión, una situación inédita en la historia del planeamiento no solamente en Andalucía sino en el conjunto del Estado. La hoja de ruta a seguir para enfrentarse a esta cuestión presentaba dos alternativas divergentes.

Por un lado, apostar por la integración plena en el crecimiento computable de las actuaciones urbanísticas heredadas. Esta alternativa produciría, cuanto menos, una detracción notable en las nuevas capacidades reclasificatorias a desarrollar en

2 Por ejemplo, según se desprende de la Memoria de Información del -hoy anulado- Plan de Protección del Corredor Litoral de Andalucía, en el planeamiento general vigente del conjunto de los municipios litorales andaluces, el número de viviendas previstas en el suelo urbanizable ordenado asciende a la sorprendente cifra de 260.348 y en el suelo urbanizable sectorizado a 210.573. La revisión de estos PGOUs tendrá que tomar en consideración esta herencia urbanística.

3 En su Norma 45.4.a, el POTA regula que no se pueden proponer crecimientos urbanos - en los primeros ocho años de vigencia del Plan General- cuyo techo poblacional supere el $30 \%$ de la población existente en el municipio y cuya extensión superficial sea mayor al $40 \%$ de la superficie del suelo urbano.

4 En la unidad subregional de la Costa del Sol Occidental, el contenido residencial de las actuaciones del suelo urbano no consolidado pendientes de desarrollo (63.075 viviendas) daría cobertura a las necesidades de vivienda de una población de 181.823 habitantes, el 45,94\% de la población actual. En el suelo urbanizable ordenado, el número de viviendas previsto es de 73.329; es decir, esta categoría de «suelo urbanizable transitorio» podrá acoger un crecimiento poblacional de 253.700 habitantes, el 64\% de la población actual de la Costa del Sol Occidental. (Datos extraídos del Documento de Análisis y Diagnóstico Territorial del POT de la Costa del Sol Occidental). 
innovaciones del planeamiento general lo cual, como podemos imaginar, contó con un rechazo generalizado tanto de Ayuntamientos como, especialmente, de propietarios de suelo y sector inmobiliario-financiero, al considerar esta medida como un freno inaceptable al desarrollo económico.

Por otro lado, se encontraba la alternativa de perpetuar el planeamiento vigente, agotar su capacidad residencial restante y, además, permitir nuevos crecimientos urbanísticos. Esta opción podría tener efectos no deseados toda vez que, la mayor parte de los modelos de ciudad previstos en los PGOU en vigor, se encontraban desacoplados a los nuevos principios que alumbraban el modelo de ciudad compacta, diversa, ambientalmente cualificada y socialmente cohesionada, regulado tanto en la LOUA como en el POTA5 ${ }^{5}$.

Ante esta disyuntiva, la Administración Autonómica optó, paradójicamente, por prolongar la vigencia de estos desfasados modelos de ciudad y alimentar su expansividad con nuevas clasificaciones de suelo urbanizable.

Entre las acciones arbitradas para hacer efectiva esta estrategia destacan: (a) las Adaptaciones Parciales a la LOUA reguladas en el «Decreto 11/2008, por el que se desarrollan procedimientos dirigidos a poner suelo urbanizado en el mercado con destino preferente a la construcción de viviendas protegidas». Este instrumento, al impedir cualquier alteración concerniente a la ordenación estructural, ha permitido prorrogar la vigencia de modelos de ciudad expansivos que, en su mayor parte y por causa de esta decisión de política territorial, aún continúan activos ${ }^{6}$; (b) la secuencia regulatoria de los campos de golf de interés turístico (Decreto 43/2008, Ley 1/2008, Decreto 309/2010 y Orden 2/2012), perpetuando la «asociación siamesa» entre campos de golf y operaciones inmobiliario-residenciales que ha inundado los territorios turísticos de la región andaluza, con especial incidencia en el dominio territorial del litoral ${ }^{7}$, (c) promover el sistemático incumplimiento de la limitación al crecimiento urbano estipulada en la Norma 45.4.a del POTA utilizando, para ello, la formulación de Instrucciones ${ }^{8}$ (1/2007, 1/2012, 1/2013 y 1/2014) redactadas, en

5 GÓRGOLAS MARTÍN, P., La planificación de la ciudad en el cambio de milenio (1997-2017). Propuestas para reconducir la herencia recibida: los casos de Casares (Málaga) y Chiclana de la Frontera (Cádiz), Tesis Doctoral, Departamento de Urbanística y Ordenación del Territorio de la Universidad de Sevilla, 2016.

6 A finales del año 2017, sólo existían 166 municipios en Andalucía (el 21,33\% del total) con planeamiento general adaptado plenamente a la LOUA. Por el contrario, el número de municipios con planeamiento adaptado parcialmente ascendía a 356 (el 45,8\% del total) y se encontraban en proceso 36 más. Fuente: www.juantadeandalucia.es

7 GÓRGOLAS MARTÍN, P., "La regulación de los campos de golf en la Comunidad Autónoma de Andalucía: ¿interés turístico o interés inmobiliario?”, en Cuadernos Geográficos núm. 57 (1), pp. 283-304.

8 Según el artículo 6.1 de la Ley 40/2015, de 1 de octubre, de Régimen Jurídico del Sector Público, los órganos administrativos podrán dirigir las actividades de sus órganos jerárquicamente dependientes mediante instrucciones 
su mayor parte, por la Secretaría General de la Consejería competente en Urbanismo y Ordenación del Territorio, al objeto de fijar los criterios para elaborar, por su órganos técnicos, los Informes de Incidencia Territorial ${ }^{9}$ que era preceptivo evacuar a la aprobación inicial de determinadas innovaciones de planeamiento general y (d) utilizar la propia planificación subregional como «golpe de ariete» para derribar la contención territorial postulada en el POTA, a través de la identificación de Áreas de Oportunidad Supramunicipal, que no integran el crecimiento urbano computable ${ }^{10}$.

Las secuelas causadas por estas «contramedidas» han sido: (a) certificar la vigencia de modelos territoriales incumplidores de las prescripciones sobre el modelo de ciudad compacta, y (b) alimentar la maquinaria de la clasificación del suelo otrogando «invisibilidad», a efectos de cumplimiento de los límites al crecimiento impuestos en la Norma 45 del POTA, a determinadas actuaciones urbanísticas: contenido residencial del suelo urbano no consolidado, suelo urbanizable ordenado y equidistribuido, Áreas de Oportunidad Supramunicipales y campos de golf de interés turístico. La Administración Autonómica, en consecuencia, fomentó el incumplimiento de sus propias normas; es decir, la inobservancia tanto de la legislación urbanística como de la normativa de la planificación regional.

La deriva interpretativa de la Norma 45 del POTA constituye, sin duda, un ejemplo paradigmático de la «condición bipolar» de las políticas territoriales y urbanísticas desarrolladas en la Comunidad Autónoma de Andalucía, ya que afecta a la medida más contundente y firme entre las adoptadas para reconducir el frenesí inmobiliario de aquellos años: limitar la capacidad de las Administraciones Locales para impulsar nuevas clasificaciones de suelo urbanizable, al objeto adoptar modelos de ciudad más sensatos y equilibrados caracterizados por los atributos de la compacidad, la densificación cualificada, la diversificación funcional, la cohesión social y la calidad ambiental.

y órdenes de servicio. Cuando una disposición específica así lo establezca, o se estime conveniente por razón de los destinatarios o de los efectos que puedan producirse, las instrucciones y órdenes de servicio se publicarán en el boletín oficial que corresponda, sin perjuicio de su difusión de acuerdo con lo previsto en la Ley 19/2013, de 9 de diciembre, de transparencia, acceso a la información pública y buen gobierno.

$9 \quad$ Estos Informes se emiten en virtud de lo establecido en la Disposición Adicional Octava de la LOUA, introducida por el artículo 29 de la Ley 13/2005, de 11 de noviembre, de Medidas para la Vivienda protegida y el Suelo y conforme a lo establecido por la Orden de 3 de abril de 2007 de la Consejería de Obras Públicas y Transporte.

10 GÓRGOLAS MARTÍN, P., "La planificación territorial de ámbito subregional en el litoral andaluz: de la «condescendencia» con el planeamiento general en vigor a la «adulteración» del modelo de ciudad regulado en el Plan de Ordenación del Territorio de Andalucía”, en Práctica urbanística, núm. 147 (2017), pp. 1-19. 
El presente artículo complementa el publicado en el número 97 de la Revista Andaluza de Administración Pública ${ }^{11}$ donde se analizaba -transcurrida una década de vigencia- el modelo de ciudad preceptuado en el POTA y se exponían las vicisitudes, polémicas y enfrentamientos que provocó, lo que devino su desnaturalización instrumentando, para ello, un conjunto de acciones -legislativas, normativas y administrativas- entre las que la «espasmódica sucesión» de Instrucciones, elaboradas por la propia Administración Autonómica, asumió un protagonismo incuestionable.

Esta política territorial errática produjo una situación de desconcierto en el urbanismo andaluz de aquellos años que causó la ralentización, más bien la paralización, de la formulación de revisiones integrales de PGOUs ante el «desnortamiento» ocasionado en algunos municipios del que, me consta por propia experiencia, algunos aún no se han repuesto ${ }^{12}$. El objetivo principal del presente artículo es profundizar en el análisis de estas Instrucciones y verificar sus oscilaciones interpretativas, al objeto de refrendar la desorientación e incertidumbre inducidas.

\section{LA INSTRUCGIÓN 1/2007: FIJAGIÓN DE CRITERIOS PARA VA- LORAR LA ADEGUACIÓN DEL PLANEAMIENTO GENERAL A LA NORMA 45 DEL POTA.}

El 10 de mayo de 2007, la Secretaría General de Ordenación del Territorio, formula la Instrucción 1/2007 cuyo objeto fue regular la elaboración y tramitación del informe de incidencia territorial que sobre los Planes Generales de Ordenación Urbanística ha de emitir, con carácter preceptivo, el órgano competente en materia de ordenación del territorio, conforme a lo dispuesto en el artículo 32, apartado 1, regla $2^{\text {a }}$ y la disposición adicional octava de la Ley 7/2002, de 17 de diciembre, de Ordenación Urbanística de Andalucía.

En su apartado IV se abordó el alcance y contenido del Informe de Incidencia Territorial del planeamiento general, a realizar en el momento procedimental de

11 GÓRGOLAS MARTÍN, P., "Diez años de vigencia del Plan de Ordenación del Territorio de Andalucía. Luces y sombras de la planificación territorial. La desnaturalización del modelo de ciudad compacta” en Administración de Andalucía. Revista Andaluza de Administración Pública, núm. 97 (2017b), pp. 319-350.

12 El caso del PGOU de Alcalá de Guadaira es sintomático de esta situación. La declaración de incumplimiento de la Norma 45 del POTA al documento aprobado inicialmente, provocó la abrupta paralización de su formulación. Al cabo de tres años se retomaron los trabajos resultando un nuevo modelo de ciudad mucho más sensato y comedido, en materia de consumo de suelo. La irrupción de la última de las Instrucciones analizadas en el artículo -la 1/2014- ha provocado que el modelo territorial declarado incumplidor haya dejado de serlo, circunstancia que ha producido una nueva paralización en la formulación del PGOU, toda vez que ha aflorado un debate acerca de la oportunidad de "volver atrás" y recuperar la propuesta de la aprobación inicial, mucho menos restrictiva en materia de crecimiento urbano y, por tanto, más afín a los requerimientos del sector promotor. 
su aprobación inicial. En su punto 2 «Valoración de las determinaciones de planeamiento» se estableció que -entre los aspectos básicos que habían de centrar la evaluación a efectuar en dicho Informe- se certificase la «justificación del crecimiento propuesto en función de parámetros objetivos referidos a la evolución en los últimos 10 años o a las nuevas circunstancias que pudieran concurrir». La Instrucción transcribe literalmente lo dispuesto en el inciso primero de la Norma 45.4.a del POTA. Además, el Informe debía comprobar que la dimensión de dicho crecimiento urbanístico, para un periodo de ocho años, se ajustaba a los parámetros establecidos en dicha disposición. A analizar los criterios establecidos en esta Instrucción a tal efecto, se destinan los siguientes epígrafes.

\section{Los criterios de la Instrucción 1/2007 para determinar la superficie computable de crecimiento urbanístico y evaluar su adecuación a la Norma 45.4.a del POTA.}

1. En primer lugar, la Instrucción dispuso que la delimitación del suelo urbano existente cumplimentase la regulación establecida en el artículo 45 de la LOUA. Este criterio implicaba la integración en la superficie de suelo urbano -a la que referir el límite porcentual de crecimiento- de todo aquel terreno que fuese clasificable como tal en aplicación del citado precepto legal. Ello incluía no sólo los terrenos resultantes de procesos reglados de producción de ciudad sino, también, aquellos ámbitos provenientes de dinámicas de ocupación irregular del suelo rústico que contasen con un importante nivel de consolidación edificatoria (al menos, las 2/3 partes del suelo apto para ser edificado).

Esta decisión fue muy criticada por determinados colectivos ecologistas ${ }^{13}$, ya que implicaba que las anomalías territoriales causadas por los asentamientos urbanísticos aflorados en el suelo no urbanizable, se utilizasen como excusa para ampliar la capacidad del crecimiento superficial admitido, resultante de aplicar el límite del $40 \%$ al volumen de suelo urbano existente ${ }^{14}$. Dependiendo de la incidencia que los

13 Durante la fase de Exposición Pública de la Aprobación Provisional I del PGOU de El Puerto de Santa María, la Federación de Ecologistas en Acción manifestó, en la Alegación formulada, su rechazo total a la incorporación en el suelo urbano "computable" de los terrenos categorizados como Suelo Urbano no consolidado provenientes del reconocimiento, para su integración urbana, de asentamientos residenciales surgidos en el Suelo No Urbanizable.

14 Por ejemplo, la clasificación de suelo urbano propuesta en el PGOU de Chiclana de la Frontera contempla una superficie total de 4.359,65 hectáreas, de las que 2.249,03 hectáreas (el 51,60\%) pertenecen a la categoría de suelo urbano no consolidado procedente de asentamientos irregulares. Su inclusión en la superficie base de cálculo provocaría un incremento adicional de crecimiento urbano admisible de casi 900 hectáreas. Como vemos, la repercusión de esta medida de cómputo puede llegar a ser determinante en determinados municipios. La constatación de esta casuística produjo la definitiva exclusión de este tipo de suelo urbano no consolidado a partir de la entrada en vigor del Decreto 2/2012. 
procesos de ocupación fraudulenta del suelo no urbanizable tuviesen en un municipio, la inclusión o no de éstos produciría diferencias sustanciales en la máxima superficie de crecimiento urbano tolerable.

Por su parte, para la contabilización del suelo urbanizable, la Instrucción 1/2007 determinó que se incluyesen todas sus categorías y usos, así como los sistemas generales incluidos y adscritos, excluyendo: (a) los suelos correspondientes a infraestructuras o dotaciones de incidencia supramunicipal, (b) los correspondientes a actuaciones urbanísticas relevantes previstas en los Planes de Ordenación del Territorio de ámbito subregional, (c) las actuaciones declaradas de interés autonómico, y (d) los suelos urbanizables no sectorizados siempre que su sectorización se prevea una vez transcurridos los ochos años correspondientes a los dos cuatrienios programables del PGOU. Este criterio presenta cuestiones del máximo interés:

1. En primer lugar, la superficie de crecimiento computable quedaba compuesta, inequívocamente, por «todas las categorías de suelo urbanizable con delimitación de sectores»; a saber, el suelo urbanizable ordenado y sectorizado. El suelo urbanizable no sectorizado -conceptuado como aquel que, presentando aptitudes para incorporarse al proceso urbanizador, no es necesario para dar acomodo a las demandas y necesidades tipificadas en el tiempo de programación del PGOU- quedaba excluido del crecimiento a considerar siempre que su sectorización se produjese después de los primeros ocho años de vigencia del PGOU y no se superasen los parámetros previstos en la Norma 45 para los dos siguientes cuatrienios. Esta decisión incitaba al cumplimiento de la pauta temporal diseñada por el POGU para materializar las extensiones urbanas programadas, evitando las interferencias distorsionantes provocadas por el desarrollo adelantado de áreas de suelo urbanizable no sectorizado, estrategia empleada con cierta recurrencia cuando concurrían problemas de gestión en algún sector del suelo urbanizable con delimitación sectorial. Esta medida, por un lado, otorgaba racionalidad a dicha secuencia temporal -en estas cuestiones «el orden de los factores puede alterar el producto»- y, por otro, desactivaba el rol de elemento flexibilizador con el que había sido concebido el suelo urbanizable no programado -antecesor del actual urbanizable no sectorizado- en la Ley Estatal de $1975^{15}$.

2. Un aspecto de vital trascendencia, como se verá a continuación, fue el tratamiento del «régimen transitorio». En concreto, destaca la decisión de incluir en el cómputo del crecimiento superficial -hasta que puedan

15 MATESANZ PARELLADA, Á., "El suelo en la legislación urbanística española", en Boletín $C F+S 51$ (2014), pp. 24-29. 
integrarse en el suelo urbano por haber alcanzado tal condición jurídica una vez urbanizados- los desarrollos urbanísticos del suelo urbanizable que aún se encontrasen en curso de ejecución.

3. Todo el suelo urbanizable con delimitación sectorial, independientemente del uso característico otorgado por el PGOU, formaba parte del crecimiento urbano contabilizable ${ }^{16}$.

4. La Norma 45.4.a del POTA especifica que los planes de ordenación del territorio de ámbito subregional determinarán criterios específicos para cada ámbito, al objeto de modular la aplicación de los límites al crecimiento urbanístico regulados en esta disposición. La interpretación que realizó la Instrucción 1/2007 de este precepto, es que las denominadas Áreas de Oportunidad Metropolitana o Supramunicipal identificadas en la planificación subregional -actuaciones urbanísticas de relevancia territorial- no debían ser incluidas en la capacidad de crecimiento conferida por dichos límites.

La vaguedad argumentativa con que muchos planes subregionales han fundamentado la ideación de esta tipología de actuaciones urbanísticas ${ }^{17}$ y su impacto en el modelo territorial resultante -al favorecer la superación del máximo crecimiento urbanístico admisible- suscitaron muchas opiniones contrarias a esta facultad otorgada a la planificación subregional por parte de la Instrucción. Y ello, porque de la lectura literal de la Norma 45.4.a del POTA no cabe concluir esta potestad. La determinación de «criterios específicos» para cada ámbito subregional fue entendida por la Administración Autonómica como una oportunidad para sortear las limitaciones impuestas al crecimiento en la citada Norma, aprovechando la indeterminación del precepto en cuestión. Seguramente, la aceleración en la formulación de planes subregionales que se produjo a partir del año

16 El artículo 17 de la LOUA define cuatro usos característicos para los diferentes sectores del suelo urbanizable: residencial, turístico, industrial y terciario. Como veremos, a partir de la entrada en vigor del Decreto $11 / 2008$ de 22 de enero, por el que se desarrollan procedimientos dirigidos a poner suelo urbanizado en el mercado con destino preferente a la construcción de viviendas protegidas, se excluyó del crecimiento computable el suelo urbanizable de uso característico industrial.

17 La Memoria de Ordenación del Plan de Ordenación del Territorio de la Aglomeración Urbana de Sevilla justifica la identificación de Áreas de Oportunidad, con la siguiente reflexión: El Plan identifica, como Áreas de Oportunidad Metropolitana de carácter residencial (veintidós) unos suelos destinados a satisfacer la demanda supramunicipal de viviendas. Estas Áreas: (a) contribuyen al reequilibrio territorial de la oferta de vivienda protegida en la aglomeración, (b) presentan buena accesibilidad desde la red metropolitana y el transporte público, (c) posibilitan infraestructuras generales urbanas determinantes para la estructura de determinados municipios y con incidencia en la estructuración y articulación de un determinado sector de la aglomeración urbana y (d) se justifican en las demandas futuras relacionadas al desarrollo de nuevos suelos productivos a los cuales se vinculan. 
$2007^{18}$ tiene que ver con esta interpretación. La reticencia histórica de los Ayuntamientos hacia la planificación territorial se tornó en un aliento incondicional para promover su formulación, al constituirse en el principal asidero con que contaban para conseguir mayores cuotas de crecimiento ${ }^{19}$.

La consecuencia lógica de esta polémica decisión de la Administración Autonómica devino su judicialización, acudiendo al pronunciamiento de los Tribunales de Justicia para dictaminar sobre su congruencia e idoneidad. En este sentido, adquiere una gran relevancia la Sentencia 5496/2014, de 5 de junio, del Tribunal Superior de Justicia de Andalucía, emitida en respuesta a un recurso interpuesto por la Federación de Ecologistas en Acción, en el que se solicitaba la anulación del Plan de Ordenación del Territorio de La Janda, entre otras cuestiones, por entender que, con la identificación de Áreas de Oportunidad, se estaba vulnerando el principio de jerarquía normativa en lo referente a los límites impuestos por la Norma 45.4 del POTA. En esta sentencia se dictaminó la nulidad del artículo 12.4 del citado plan subregional, en el que se determinaba la exclusión del cómputo del crecimiento urbanístico de dichas actuaciones pretendidamente estratégicas ${ }^{20}$.

5. Además de las Áreas de Oportunidad identificadas en los planes subregionales, la Instrucción 1/2007 dispuso la detracción -del crecimiento urbano cuantificable- de aquellas actuaciones declaradas de interés autonómico.

18 De los 17 Planes Subregionales en vigor, 5 son anteriores al POTA (Aglomeración Urbana de Granada, Poniente de Almería, Sierra de Segura (Jaén), Ámbito de Doñana y Bahía de Cádiz), 2 son coetáneos al POTA ( Litoral Occidental de Huelva y Litoral Oriental-Axarquía de Málaga) y 10 son posteriores al POTA (Levante de Almería, Aglomeración Urbana de Sevilla, Aglomeración Urbana de Málaga, Costa Noroeste de Cádiz, La Janda, Aglomeración Urbana de Almería, Campo de Gibraltar, Costa Tropical, Sur de Córdoba y Aglomeración Urbana de Jaén). En conclusión, 13 Planes Subregionales (el 72\% del total) son coetáneos o posteriores al POTA.

19 GORGOLAS MARTÍN, P. (2017 a).

20 En su Fundamento Jurídico Noveno, el Tribunal afirma que el artículo 12.4 del POT de La Janda, donde se regula la exclusión del cómputo del crecimiento de las Áreas de Oportunidad, no cumple con la Norma 45.4 del POTA, entendiendo que la planificación territorial no está justificando la alteración sustancial de los parámetros objetivos de crecimiento deducidos de las tendencias de la última década, así como tampoco está determinando "criterios específicos para la Unidad Territorial de La Janda", sino que está promoviendo la " no aplicación" de la Norma 45.4 vulnerando el contenido de la misma al infringir su carácter vinculante. La Sentencia 1129/2016, de 14 de marzo, del Tribunal Supremo en el recurso de casación 3187/2014 presentado por la Junta de Andalucía contra la Sentencia 5496/2014 del TSJA, falla desestimar dicho recurso. En su Fundamento Jurídico Cuarto, afirma que si se admite que efectivamente los planes territoriales puedan establecer criterios específicos con base en el indicado artículo 45.4, tampoco resulta descabellado considerar que tales criterios han de moverse dentro del ámbito de los límites establecidos por dicho precepto reglamentario indicado; en otros términos, el legítimo establecimiento de tales criterios específicos tampoco equivale a la lisa y llana exención de los parámetros establecidos por dicho precepto. 
Esta decisión tuvo una especial repercusión en la incidencia territorial de los denominados «campos de golf de interés turístico» ${ }^{21}$. En el apartado 4 del artículo 1 del Decreto 43/2008, de 12 de febrero, regulador de las condiciones de implantación y funcionamiento de campos de golf en Andalucía, se dictaminó que, por su carácter de equipamiento deportivo especializado que aporta valores añadidos a la oferta turística regional, se entenderá que los campos de golf que se implanten en Andalucía tienen incidencia territorial e interés supramunicipal, a los efectos previstos en la legislación en materia de ordenación del territorio y urbanismo. $\mathrm{Al}$ tiempo, el Decreto obligaba a la planificación subregional y al planeamiento general a integrar, en el modelo territorial establecido, las iniciativas de campos de golf que hubiesen sido declaradas de interés turístico.

Además, a raíz de la entrada en vigor de la Ley 1/2008, de 27 de Noviembre, de medidas tributarias y financieras de impulso a la actividad económica de Andalucía y de agilización de los procedimientos administrativos, los campos de golf declarados de interés turístico comenzaron a tener la consideración de «actuaciones de interés autonómico». En su Disposición Final Segunda se incorporó un nuevo Título $\mathrm{V}$ a la Ley 1/1994 de Ordenación del Territorio de Andalucía (LOTA), denominado «de las declaraciones de campos de golf de interés turístico», en el que se determinó la innecesaridad de incluir este tipo de iniciativas en los planes subregionales para admitir su implantación bastando, para ello, la aprobación de la declaración por el Consejo de Gobierno. Para los casos que existiese plan subregional en vigor, la ley añadió un párrafo final al apartado 2 del artículo 38 de la LOTA con el siguiente tenor literal: la declaración por el Consejo de Gobierno de actuaciones de interés autonómico cuyas determinaciones supongan una alteración de los Planes de Ordenación del Territorio de ámbito subregional implica la modificación de dichos planes.

El efecto en la evaluación de la incidencia territorial de los PGOUS que hubiesen de integrar estas actuaciones, fue inmediato: desde la entrada en vigor de la Ley 1/2008, las iniciativas de campos de golf declaradas de interés turístico quedaron excluidas del cómputo del crecimiento máximo admisible regulado en la Norma 45.4.a del POTA, exista o no planeamiento subregional de referencia, al adquirir la condición de «actuaciones de interés autonómico».

21 BARRANCO VELA, R., "La problemática jurídica de los campos de golf (II): condiciones ambientales y urbanísticas. Especial referencia al Decreto andaluz de campos de golf”, en Revista andaluza del derecho del deporte, núm. 8 (2010), pp. 325-370. 


\section{Los criterios establecidos en la Instrucción 1/2007 para el cómputo del crecimiento poblacional.}

Para la Instrucción 1/2007, la población a la que referir el límite porcentual de crecimiento poblacional de la Norma 45.4.a, era la correspondiente al Padrón Municipal de Habitantes en el momento de la aprobación inicial del Plan. Esta regla fue causa de una gran polémica debido al importante lapso temporal que suele mediar entre la aprobación inicial de un PGOU y su aprobación definitiva y las diferencias sustantivas que -en función de la dinámica de crecimiento poblacional que haya seguido el municipio- podía haber entre la población existente en ambos momentos procedimentales. Esta disputa quedó resuelta en el Decreto 11/2008 de 22 de Enero, en cuya Disposición Adicional segunda -apartado 4- se reguló que para la determinación del parámetro de crecimiento de población se referirá el dato de población existente para el conjunto de municipios de Andalucía al momento de la aprobación definitiva de la revisión o nueva redacción de cada Plan General de Ordenación Urbanística.

Para calcular el incremento de población, la Instrucción 1/2007 fijó las siguientes reglas:

1. La medición del techo residencial establecido por el planeamiento general en su programación bicuatrienal, tenía que incluir las viviendas previstas en el suelo urbano no consolidado y el suelo urbanizable con delimitación de sectores (ordenado y sectorizado). La Instrucción era clara en esta cuestión: el contenido residencial de «todas» las actuaciones contempladas -tanto las de transformación y/o regularización del suelo urbano no consolidado, como las de nuevo crecimiento- computaba a efectos del cálculo del incremento poblacional, salvo que la ejecución de la urbanización estuviese concluida y las viviendas materializadas. Así, el suelo urbanizable que hubiese alcanzado la condición jurídica de suelo urbano -por haber satisfecho las condiciones de urbanización estipuladas en el artículo 45 de la LOUA- quedaba excluido del crecimiento superficial, pero ello no implicaba el detraimiento de su contenido residencial del máximo crecimiento poblacional permitido. La clasificación del suelo es un «concepto dinámico»; es decir, un suelo urbanizable pasa a incorporarse automáticamente al suelo urbano cuando ha concluido la ejecución material de las obras de urbanización pertinentes, pero este tránsito no puede arrastrar al contenido residencial propuesto -transfigurándolo de «vivienda potencial» en «vivienda existente»- por el simple hecho de que el suelo soporte se encuentre urbanizado.

2. La conversión entre vivienda y población se tenía que realizar estimando el tamaño medio de hogares en función de datos objetivos aportados por el Instituto Nacional de Estadística o el Instituto de Estadística de Andalucía. 
Esta regla estaba cargada de indefinición, porque no fijaba el concepto estadístico sobre el que realizar el cálculo estimativo requerido. Además, al aplicarse de manera individualizada a cada municipio ocasionó oscilaciones interpretativas, dada la diferencia existente en la caracterización del parque de viviendas de determinados municipios, especialmente aquellos de fuerte vocación turística donde suele ser mayoritaria la «vivienda no principal», concepto estadístico que integra tanto la vivienda vacía como la segunda residencia. Al referir, en estos municipios, el parque total de viviendas existente -principal y no principal- a la población censada, los ratios habitantes/vivienda que se obtenían eran extremadamente reducidos, produciéndose importantes desviaciones respecto a municipios con mayor porcentaje de vivienda principal y población permanente, lo cual fue percibido por éstos como un agravio comparativo porque, a igualdad de incremento poblacional admisible, la equivalencia resultante en número de viviendas era considerablemente inferior. ${ }^{22}$

3. No obstante, en cualquier caso, el incremento poblacional a proponer en los PGOUs, debía justificarse en un estudio de demanda de vivienda que respondiese, además, a las determinaciones del artículo 9.C de la LOUA, donde se regula la necesidad de atender a la demanda de vivienda socialy otros usos de interés público de acuerdo con las características del municipio y las necesidades de la población. La Instrucción 1/2007 especificaba que el crecimiento poblacional proyectado se ajustase a las dinámicas tendenciales diagnosticadas durante la última década y que, por tanto, sólo en casos adecuadamente justificados podría desviarse de éstas. Ello quiere decir que, si del estudio de estas tendencias, el crecimiento deducido era inferior al obtenido de los límites porcentuales de la Norma 45.4.a, agotar la capacidad residencial conferida por éstos implicaba un refuerzo argumentativo del PGOU, amparado en estrategias de potenciación territorial del municipio en cuestión. Sin embargo, la inmensa mayoría de las revisiones de planeamiento general que se han formulado desde la entrada en vigor del POTA han eludido, con mayor o menor fortuna, esta fundamentación acudiendo directamente

22 El caso del municipio de Casares (Málaga) es sorprendente y sirve para ilustrar esta reflexión. En este municipio la ratio habitante censado/vivienda que se obtiene es, aproximadamente, de 0,35 revelando la problemática asociada a los territorios turísticos extremadamente desestacionalizados por el protagonismo de la segunda vivienda vacacional. ¿Cuál debe ser el factor conversor entre vivienda y techo poblacional aplicable en este tipo de municipios? ¿Cómo ha de interpretarse la regla establecida en la Instrucción 1/2007? 
a adecuar el modelo de ciudad propuesto a las máximas capacidades de crecimiento admitidas por la Norma 45.4. $\mathrm{a}^{23}$.

\section{LA ALTERAGIÓN DE LOS GRITERIOS DE LA INSTRUGGIÓN 1/2007 DURANTE SU VIGENCIA: LOS INFORMES DE INCI- DENCIA TERRITORIAL.}

La Instrucción 1/2007 ha sido la más longeva de cuantas ha formulado la Administración Autonómica de la Junta de Andalucía para evaluar la incidencia territorial del planeamiento general. Sus criterios de «medición y cómputo del crecimiento urbano admisible» han estado vigentes 6 años, hasta la formulación de la Instrucción 1/2013, toda vez que la anterior -Instrucción 1/2012-, como se expondrá a continuación, no introdujo cambios en estos criterios, sino una nueva fórmula de cálculo del techo poblacional de las actuaciones residenciales a consecuencia de la entrada en vigor de la Ley 2/2012 de modificación de la Ley 7/2002 de Ordenación Urbanística de Andalucía, que alteró la determinación de la ordenación estructural de los PGOU relativa al establecimiento de la densidad residencial.

En estos años de vigencia, entre los que se encuentra el bienio (2007-2008) previo a la deflagración de la burbuja inmobiliaria, se reclamó -desde la Administración Local alentada por propietarios de suelo y promotores inmobiliarios- la flexibilización de los criterios explicitados en la Instrucción 1/2007, para lo cual se emplearon dos vías alternativas y complementarias: (a) por un lado, la elaboración de fórmulas normativo-reglamentarias -Decreto 11/2008- donde se modificaron algunas disposiciones del POTA, entre las que destaca la exclusión, del crecimiento urbanístico computable, del suelo urbanizable de uso característico industrial; y, lo más preocupante, (b) la evacuación de los propios Informes de Incidencia Territorial donde es apreciable y constatable la adopción de criterios divergentes en relación, básicamente, con el aspecto más conflictivo de la interpretación de la Norma 45.4.a: la «contabilización plena» de todas las actuaciones residenciales previstas en el suelo urbano no consolidado y suelo urbanizable con delimitación sectorial que no podían ser excluidas a causa de su incidencia supramunicipal (Áreas de Oportunidad identificadas en planes subregionales y actuaciones de interés autonómico).

En especial, el conflicto se centró en el conjunto de actuaciones heredadas del planeamiento objeto de revisión que se encontraban en desarrollo, donde la casuística a evaluar era muy amplia: (a) ámbitos que sólo contaban con su planeamiento derivado aprobado definitivamente, (b) actuaciones que, ordenadas en detalle, no habían concluido su «fase documental» (proyectos de urbanización y reparcelación en

23 Los casos, expuestos en este artículo, de los PGOUs de El Puerto de Santa María y Alcalá de Guadaira, ejemplifican con nitidez esta afirmación. 
tramitación), (c) aquellas que se encontraban, además de ordenadas en detalle, equidistribuidas y, finalmente, (d) actuaciones cuya urbanización se encontraba en curso de ejecución. Computar o no esta herencia urbanística resultaba vital porque, de la decisión adoptada en el Informe de Incidencia Territorial, dependía la capacidad del nuevo PGOU para promover nuevas operaciones residenciales de transformación de la ciudad existente y, sobre todo, nuevas clasificaciones de suelo urbanizable.

Como trataré de constatar a continuación, la Administración Autonómica cedió a la presión ejercida por el sector promotor-inmobiliario para, aprovechando la elaboración de estos informes, introducir nuevas interpretaciones -sobre la exclusión de determinadas actuaciones del crecimiento computable- que se apartaban de los criterios especificados en la Instrucción 1/2007. El insoportable peso de la herencia recibida por el planeamiento general objeto de revisión, debía ser aligerado para permitir una adecuada musculación del crecimiento urbanístico y facilitar la incorporación de nuevas actuaciones residenciales que actuasen de materia prima para seguir alimentando la voracidad de la producción inmobiliaria. Esta actitud, al no estar avalada por ninguna regla correctamente explicitada en, al menos, una nueva Instrucción produjo, como era previsible, interpretaciones contradictorias en los Informes de Incidencia Territorial confeccionados en esos años y generó agravios comparativos entre PGOUs coetáneos.

La interpretación comúnmente aplicada en dichos informes ${ }^{24}$, fue considerar no computables a efectos del cumplimiento de la Norma 45.4.a del POTA, todas aquellas «actuaciones transitorias» -tanto del suelo urbanizable como del suelo urbano no consolidado- que contasen con la ordenación detallada aprobada definitivamente y sus instrumentos de ejecución de la urbanización y de gestión -Proyecto Urbanización y Proyecto de Reparcelación- aprobados, al menos, inicialmente. Ello, por considerar razonable que, en el plazo que media entre la aprobación inicial del PGOU y su aprobación definitiva, estos suelos alcanzarían un nivel de ejecución suficiente para ser considerados suelos urbanos, atendiendo a la celeridad característica de la producción de ciudad en los años del boom inmobiliario.

Esta sorprendente sustracción afectaba tanto al crecimiento superficial como al crecimiento poblacional admitiendo, para éste, la detracción de las viviendas previstas en dichas actuaciones. En este aspecto es donde la transgresión con el criterio

24 Debo expresar, en este punto, la enorme dificultad existente para acceder a los Informes de Incidencia Territorial evacuados en esta época (2007-2013). La información de los PGOU contenida en la página web de la Consejería de Medio Ambiente y Ordenación del Territorio (aplicación Situ@) no incorpora este documento vital para evaluar la adecuación de aquellos a los principios de la planificación territorial. Por consiguiente, el análisis incorporado en el texto procede, en su mayor parte, de trabajos profesionales del autor. También debo agradecer la información facilitada por los servicios técnicos del Ayuntamiento Jerez de la Frontera. 
de la Instrucción 1/2007 es más impactante, ya que se trataba de operaciones urbanísticas que, en su mayor parte, ni siquiera habían iniciado la ejecución de la obra urbanizadora.

La decisión adoptada por la Administración Autonómica fue, por tanto, invisibilizar el «régimen transitorio» a efectos de aplicación de la Norma 45.4.a del POTA alentando, con ello, su incumplimiento porque la tendencia seguida por las revisiones de los PGOUs era agotar el máximo crecimiento urbanístico admitido -especialmente, el relativo al incremento poblacional- en actuaciones cuantificables con lo que, en realidad, los límites regulados estaban siendo sistemáticamente superados ${ }^{25}$. Sin embargo, la contravención perpetrada no concluyó en la invisibilización de la transitoriedad. Así, ante la presión ejercida por un Ayuntamiento de la importancia de Jerez de la Frontera, se admitió eliminar del cómputo todas las actuaciones del suelo urbano no consolidado heredadas del planeamiento objeto de revisión que, asumidas por el nuevo PGOU, no habían iniciado su desarrollo. Es decir, sin mediar oficialidad alguna, a partir de este momento, en el suelo urbano no consolidado sólo contabilizarían, para la determinación del incremento poblacional, las actuaciones ex novo ideadas en las innovaciones de los PGOUS ${ }^{26}$.

En conclusión, en los años de vigencia de la Instrucción 1/2007, los Informes de Incidencia Territorial fueron alterando las «reglas del juego» en función de prerrogativas y presiones de los Ayuntamientos implicados. El nivel generalizado de desconcierto e incertidumbre causado por esta forma de proceder, es fácilmente imaginable. Las actuaciones computables a efectos del cumplimiento de la Norma 45 del POTA parecían ser objeto de negociación entre las Corporaciones Locales y la Administración Autonómica sin que hubiese control sobre las repercusiones ocasionadas y los agravios comparativos causados. Una suerte de «urbanismo concertado interadmi-

25 El Informe de Incidencia Territorial del PGOU de El Puerto de Santa María (Cádiz) el 29 de enero de 2010. En su página 2 se expresa que "para satisfacer las necesidades de viviendas totales el PGOU propone para el suelo urbano no consolidado y para el suelo urbanizable sectorizado, excluido el transitorio y descontadas las viviendas de la Zerpla-2 "Cantarranas" (...) un total de 9.497 viviendas (aclarar que la ZERPLA-2 se corresponde con un Área de Oportunidad identificada en el plan subregional de la Bahía de Cádiz). La máxima capacidad de crecimiento poblacional deducida de la Norma 45.4.a del POTA era de 27.253 habitantes (el 30\% de la población de referencia, 90.844 habitantes); es decir, 11.355 viviendas equivalentes. El número total de viviendas excluidas del cómputo del crecimiento poblacional fue de 10.458 (un 110\% de las 9.497 computables). Por causa de esta decisión, el techo residencial total admitido en el PGOU de El Puerto de Santa María ascendió a 19.955 viviendas, equivalentes a una población de 47.892 habitantes; es decir el 52,72\% de la población de referencia.

26 El PGOU de Jerez de la Frontera no computó el crecimiento poblacional contenido en Unidades de Ejecución no desarrolladas del PGOU anterior para las que la Revisión mantuvo sus determinaciones urbanísticas. Esta nueva regla no consta, expresamente, en el Informe de Incidencia Territorial (elaborado el 4 de febrero de 2008) que, por el contrario, si referencia la exclusión del cómputo de los suelos urbanizables transitorios (página 3 del Informe). 
nistrativo» o de «urbanismo consuetudinario» sustentado en la formulación de los impredecibles Informes de Incidencia Territorial, que iban cambiando los criterios a aplicar en función de la fuerza negociadora ejercida por los Ayuntamientos.

Por ello, no es de extrañar que, sin previo aviso, la Administración Autonómica cambiase, repentinamente, de rumbo mediante un golpe violento de timón y comenzase a aplicar, explícitamente, las reglas de la Instrucción 1/2007 considerando crecimiento cuantificable todo el suelo urbanizable transitorio -independientemente de su nivel de desarrollo- al entender que: (a) su exclusión del crecimiento superficial quedaba vinculada a la adquisición de la condición jurídica de suelo urbano, una vez certificada la conclusión de la urbanización en cumplimiento del artículo 45 de la LOUA, y (b) sólo las viviendas materializadas podían ser detraídas del crecimiento de población admisible. Obviamente, las consecuencias para los Ayuntamientos afectados fueron demoledoras ${ }^{27}$.

Por último, conviene apuntar que, del análisis de los Informes de Incidencia Territorial a los que se ha tenido acceso para elaborar este $\operatorname{artículo}^{28}$, se constata que ninguno de los municipios analizados presentaban una dinámica tendencial de crecimiento poblacional que avalase siquiera alcanzar el 30\% admitido para los 8 primeros años de vigencia del PGOU, lo cual confirma que el cumplimiento de la Norma 45 del POTA quedó, con carácter general, recluido a la observancia de los límites impuestos, aun cuando éstos no respondiesen a las tendencias diagnosticadas en la última década, tal y como regula el inciso primero del apartado 4.a de la citada disposición.

27 Apenas seis meses después (26 de julio de 2010) del caso expuesto para El Puerto de Santa María, la Delegación Provincial de Sevilla de la Consejería de Obras Públicas y Vivienda evacuó el Informe de Incidencia Territorial a la aprobación inicial del PGOU de Alcalá de Guadaira (Sevilla). El documento, en lo relativo al cumplimiento de la Norma 45 del POTA, empleó idénticos criterios a los expuestos para El Puerto de Santa María. De esta forma, para un total de 28.661 viviendas realmente propuestas, propuso computar, exclusivamente 8.463, descontando, para ello, las 9.693 viviendas del suelo urbanizable transitorio y las 10.505 incluidas en las Áreas de Oportunidad Metropolitana identificadas en el Plan Subregional de la Aglomeración Urbana de Sevilla. No obstante, el Informe de Incidencia Territorial aplica nuevos criterios interpretativos en sintonía con la redacción original de la Instrucción 1/2007. Así, en su página 6 expresa que el Plan General no computa el impropiamente denominado suelo urbanizable transitorio derivado del Plan vigente que, encontrándose en diversas fases de desarrollo, aún no ha adquirido la condición de suelo urbano. De esta manera, el Informe de Incidencia Territorial considera computables a efectos del cumplimiento de la Norma 45 del POTA un total de 18.056 viviendas, que suponen 43.334 habitantes, cifra que representa el $61,77 \%$ de la población existente, superando ampliamente el crecimiento máximo en ocho años estipulado en la citada Norma.

28 Los Informes analizados se corresponden con los municipios de Montilla y Puente Genil- en la provincia de Córdoba-, Marbella y Ronda en la provincia de Málaga, Los Barrios, San Fernando, Jerez de la Frontera, el Puerto de Santa María y Chiclana de la Frontera en la provincia de Cádiz y Alcalá de Guadaira y Morón de la Frontera en la provincia de Sevilla. 


\section{LA INSTRUCGIÓN 1/2012: ADEGUACIÓN A LA LEY 2/2012, DE 30 DE ENERO, DE MODIFICACIÓN DE LA LEY 7/2002, DE 17 DE DICIEMBRE, DE ORDENACIÓN URBANÍSTICA DE ANDALUCÍA.}

Esta Instrucción tuvo como objeto establecer criterios, orientaciones y aclaraciones para los distintos órganos urbanísticos de la Consejería de Obras Públicas y Vivienda en relación con la entrada en vigor y aplicación de la «Ley 2/ 2012, de 30 de enero, de modificación de la Ley 7/2002, de 17 de diciembre, de Ordenación Urbanística de Andalucía». El análisis desarrollado en este apartado, dado el objetivo del artículo, se centrará en la afectación al cumplimiento de la Norma 45.4.a del POTA derivada de la nueva regulación que, en materia de densidad, establece esta ley modificando el artículo 10.1.A) d) de la LOUA ${ }^{29}$.

Esta reforma legislativa -aplicable en todos aquellos PGOU sobre los que, al menos, no hubiese recaído la aprobación inicial antes del 28 de febrero de 2012, fecha de su entrada en vigor-, flexibilizó la asignación de la densidad residencial en los sectores del suelo urbano no consolidado y del suelo urbanizable sectorizado. Por consiguiente, resultó imprescindible fijar un nuevo criterio para calcular el techo poblacional de estas actuaciones urbanísticas al no poder deducirse, como habitualmente había ocurrido, del número de viviendas asociado a la densidad máxima, determinación que formaba parte de la ordenación estructural de los PGOUS en la redacción original de la LOUA. Para ello, se definió un parámetro de equiparación entre edificabilidad residencial y número de habitantes. Así, en relación a la reserva de sistemas generales de espacios libres regulada en el artículo 10 de la LOUA, la Ley 2/2012 introdujo la posibilidad de fijarla por población o «por cada 40 metros cuadrados de techo edificable destinado a uso residencial». Por lo tanto, en virtud de esta disposición, la Instrucción 1/2012 adoptó el criterio de calcular la población máxima en los sectores de uso global residencial previstos en el PGOU -cuando no tengan determinada expresamente su densidad- aplicando este parámetro. Este criterio supuso una importante innovación, ya que desvinculaba el concepto de población equivalente de la «densidad», asociándolo a la «edificabilidad residencial».

Ello quiere decir que la equivalencia entre habitantes y viviendas pasó a depender, sustancialmente, del techo edificable asignado por el planeamiento urbanístico

$29 \quad$ En el citado artículo se establece los Planes Generales de Ordenación Urbanística asignarán usos y edificabilidades globales para las distintas zonas del suelo urbano y para los sectores del suelo urbano no consolidado y del suelo urbanizable ordenado y sectorizado, así como sus respectivos niveles de densidad que se distribuirán entre los siguientes parámetros: (1) densidad muy baja: 5 o menos viviendas por hectárea, (2) densidad baja: más de 5 y hasta 15 viviendas por hectárea, (3) densidad media-baja: más de 15 y hasta 30 viviendas por hectárea, (4) densidad media: más de 30 y hasta 50 viviendas por hectárea, (5) densidad alta: más de 50 y hasta 75 viviendas por hectárea y, (6) densidad muy alta: más de 75 vivienda por hectárea. 
a las unidades residenciales, invalidando, en cierto modo, el valor establecido en el artículo único de la Orden de 29 de Septiembre de 2008 que fijaba un coeficiente de 2,4 habitantes por vivienda, aplicable en toda la región andaluza. ${ }^{30}$ Este nuevo criterio impactó de nuevo, negativamente, en los municipios turísticos, donde una parte importante de los crecimientos urbanísticos -en especial, los vinculados a ofertas de campos de golf- se caracterizaban por el establecimiento de bajas densidades residenciales asociadas al predominio de viviendas unifamiliares.

\section{LA INSTRUCGIÓN 1/2013: EL URBANISMO ANDALUZ PAREGE ENCAMINARSE POR LA SENDA DE LA SOSTENIBILIDAD.}

En la Exposición de Motivos de esta Instrucción se afirmaba que su objeto era desarrollar los criterios para la medición de estos crecimientos urbanisticos que deben adoptarse por los distintos órganos de esta Consejería, tanto a nivel central por la Secretaría General de Ordenación del Territorio y la Dirección General de Urbanismo, como por los Servicios de Urbanismo y las Oficinas de Ordenación del Territorio de las distintas Delegaciones Territoriales, a la hora de emitir los informes de incidencia territorial de los distintos instrumentos de planeamiento general, y en los informes previos a la resolución definitiva de los mismos. Funto a la especificación de los criterios para la medición de la población y de la superficie del suelo urbano existente que deben tomarse como base para la medición de los crecimientos urbanísticos propuestos y la especificación de los criterios para la contabilización de estos crecimientos, en esta Instrucción se aborda, con especial detenimiento, la medición de los crecimientos urbanísticos según la situación temporal en la que se tramita el instrumento de planeamiento a valorar, en relación con la situación en que se encuentra el planeamiento general vigente en el municipio, ya esté adaptado o no a las determinaciones del Plan de Ordenación del Territorio de Andalucía.

Los nuevos criterios de medición del crecimiento urbanístico contemplados en esta Instrucción, supusieron una auténtica revolución respecto a las adulteraciones interpretativas -expuestas en el apartado precedente- adoptadas en los Informes de

30 Con este nuevo criterio de cálculo poblacional el parámetro de 2,4 habitantes/vivienda sólo es válido en aquellas unidades residenciales de $96 \mathrm{~m} 2$ de techo edificable. Ello condiciona de manera determinante la atribución de la edificabilidad residencial en áreas o sectores, especialmente los de baja o muy baja densidad, donde las ratios $\mathrm{m} 2$ de techo/vivienda suelen ser bastante superiores a la cantidad anterior, dado que la opción tipológica prioritaria será la vivienda unifamiliar. Así, por ejemplo para ratios de $120 \mathrm{~m} 2$ de techo / vivienda, muy comunes en viviendas unifamiliares adosadas, el número de habitantes equivalentes asciende a 3; para ratios de $160 \mathrm{~m} 2$ /vivienda, habituales en viviendas pareadas, el número de habitantes asciende a 4 y, para ratios de $200 \mathrm{~m} 2$ /vivienda, habituales en tipologías de vivienda unifamiliar aislada, los habitantes equivalentes ascienden a 5. Es decir, a partir de la entrada en vigor de la Ley 2/2012 y de la Instrucción 1/2012, el techo poblacional de una vivienda unifamiliar aislada duplica al de una vivienda colectiva. Este criterio modula más certeramente la capacidad habitacional de una vivienda en función de su techo edificable mitigando la tentación a la que sucumbieron muchos PGOU de desajustar los parámetros de edificabilidad y densidad, elevando artificialmente el techo edificable de las unidades residenciales contempladas. 
Incidencia Territorial elaborados durante la vigencia de la Instrucción 1/2007. La Administración Autonómica pareció realizar un «examen de conciencia» corrigiendo una parte sustantiva de sus planteamientos anteriores. Con total seguridad, la experiencia novedosa de un gobierno de coalición entre el Partido Socialista e Izquierda Unida, unido a la profunda crisis económico-social que estaba sufriendo la Comunidad a causa, principalmente, del desenfreno inmobiliario al que, en buena parte, había contribuido la propia Administración Autonómica -con el empeño mostrado en desvirtuar los principios del modelo de ciudad al que debían tender los municipios andaluces en aplicación de las determinaciones de la LOUA y del POTAdevino el auténtico "propósito de enmienda» que significó la formulación de esta Instrucción 1/2013.

Poco -más bien nada- de lo evaluado en los Informes de Incidencia Territorial confeccionados en el periodo de vigencia de la Instrucción 1/2007, será válido a partir de este momento. Además, no podemos olvidar el impacto causado -en las políticas territoriales a instrumentar- por la aprobación de dos Decretos determinantes: el Decreto 2/2012, de 10 de enero, por el que se regula el régimen de las edificaciones y asentamientos existentes en suelo no urbanizable ${ }^{31}$ y el Decreto-Ley 5/2012, de 27 de noviembre, de medidas urgentes en materia urbanística y para la protección del litoral ${ }^{32}$.

La Instrucción 1/2013, en primer instancia, clarificó que la verificación del cumplimiento de la Norma 45 del POTA era aplicable a las revisiones integrales del planeamiento general, a las revisiones parciales y modificaciones del mismo -que tengan por objeto nuevas clasificaciones de suelo urbanizable-, así como a los Planes de Ordenación Intermunicipal y los Planes de Sectorización. Al tiempo, dilucidó que la certificación, por parte de la Administración Autonómica, de su adecuación a la planificación territorial se produjese en dos momentos procedimentales: tras la aprobación inicial, mediante los Informes de Incidencia Territorial y tras la aprobación provisional, en el informe previo a la aprobación definitiva.

\section{La reinterpretación de los criterios aplicables para evaluar la adecuación del planeamiento general a la Norma 45 del POTA.}

Significadas estas cuestiones de carácter general, la Instrucción 1/2013 abordó la «reinterpretación» de los criterios a seguir para evaluar la adecuación de los

31 OLMEDO PÉREZ, S., "Reflexiones sobre las edificaciones clandestinas en suelo no urbanizable en Andalucía y los intentos de la Comunidad Autónoma de Andalucía para su reconducción", en Práctica Urbanística, núm. 139 (2016), pp. 32-61.

32 ZAMORANO WISNES, J., "Comentarios al Decreto 5/2012 de medidas urgentes en materia urbanística y para la protección del litoral”, en Administración de Andalucía. Revista Andaluza de Administración Pública, núm. 85 (2013), pp. 407-425. 
crecimientos urbanos contemplados en los instrumentos de planificación urbanística antes relacionados, a la Norma 45.4.a del POTA.

Así, sobre la justificación del crecimiento urbano propuesto, esta Instrucción impuso, de manera taxativa, que la memoria de los instrumentos de planificación objeto de evaluación, incluyese una justificación expresa de la adecuación de las propuestas de crecimiento a las determinaciones del POTA y a la ordenación dispuesta en los Planes de Ordenación del Territorio subregionales, en cumplimiento de los artículos 9.A.a) y 19.1.2) de la LOUA. La ausencia de esta justificación que, como se ha comentado con anterioridad, caracterizó a muchos de los PGOUS de esa época, podría determinar la suspensión de su aprobación definitiva. Es decir, para la Instrucción 1/2013 los límites al crecimiento establecidos en la Norma 45.4.a del POTA no debían considerarse un criterio general de crecimiento, sino un máximo admisible. A partir de este momento, por tanto, estos valores porcentuales dejaron de conceptuarse como una meta alcanzable -o superable, incluso-, sin atender al crecimiento tendencial deducido del diagnóstico de la última década, como hasta ahora había ocurrido. O, dicho más explícitamente, todos aquellos municipios cuyo índice de crecimiento anual acumulativo fuese inferior al 3,75\% - de los 778 municipios andaluces, apenas 29 alcanzan o superan este porcentaje-, difícilmente podrían ajustarse -salvo indicación expresa de un plan subregional que haya establecido estrategias territoriales de ordenación de las que se derive la superación de las dinámicas detectadas- a las limitaciones definidas en la citada Norma.

Uno de los cambios más significativos -entre los incluidos en esta Instrucciónfue el referido a la concreción de la superficie de suelo urbano a la que aplicar el límite porcentual de crecimiento superficial que, recordemos, debía integrar los terrenos que cumplían con las condiciones establecidas en el artículo 45 de la LOUA para poder contar con dicha clasificación. La Instrucción 1/2013 mantuvo este criterio general, si bien enfatizó la obligación de realizar un ejercicio riguroso a la hora de definir el perímetro del suelo urbano, para evitar sobredimensionamientos artificiales. Por otra parte, la irrupción del Decreto $2 / 2012^{33}$ introdujo una importantísima excepción a esta regla general al disponer que no computará como suelo urbano existente la superficie perteneciente a la categoría de suelo urbano no consolidado conformada por asentamientos irregulares surgidos en suelo no urbanizable. Esta nueva regulación resultó determinante, especialmente para aquellos municipios de la

33 El artículo 18.1.A.a) del Decreto 2/2012, especifica que "No se computará como suelo urbano existente los terrenos ocupados por los asentamientos producidos de forma irregular a los que el Plan General de Ordenación Urbanística otorgue la clasificación de suelo urbano no consolidado". Con esta norma se pretende evitar crecimientos no justificados del suelo urbanizable en municipios en los que, por existir gran número de asentamientos urbanísticos ilegales, la superficie base de cálculo se vería artificialmente incrementada como consecuencia de la incorporación de estos asentamientos urbanísticos como suelo urbano no consolidado. 
geografía andaluza donde la existencia de asentamientos irregulares integrables en los modelos de ciudad tenía -y tiene- una presencia y proporción relevante ${ }^{34}$.

Las reglas establecidas para el cómputo del crecimiento superficial, son prácticamente idénticas a las de la Instrucción 1/2007, si bien se realizó una necesaria, concreta y específica puntualización para evitar interpretaciones en contrario: los terrenos que se proponga clasificar como "suelo urbanizable transitorio" se incluirán para el cómputo del crecimiento superficial, excepto aquellos que tengan la urbanización finalizada conforme al planeamiento urbanístico en ejecución. Con esta aclaración, la Instrucción 1/2013 certificó la inclusión en el crecimiento computable de esta categoría de suelo urbanizable, principal caballo de batalla de los Informes de Incidencia Territorial de aquella época ${ }^{35}$. Esta regla general contaba con una serie de excepciones, donde también se incorporaron novedades sustanciales:

1. Se introdujo, expresamente, la eliminación del suelo urbanizable de uso global industrial regulada en el Decreto 11/2008 y se mantuvo la detracción de las Áreas de Oportunidad establecidas en la planificación subregional. La Instrucción 1/2013 no hizo referencia alguna a las actuaciones de interés autonómico, si bien, para los casos concretos de los campos de golf de interés turístico, esta indeterminación quedaba solventada en su propia regulación (Ley 1/2008 y Decreto 309/2010).

2. Se adoptaron nuevos criterios de supresión a causa de la entrada en vigor del Decreto 2/2012. Así, según el apartado 1.A.b) de su artículo 18, en el suelo urbanizable correspondiente a asentamientos urbanísticos integrables, era deducible la superficie de las parcelas ocupadas por edificaciones existentes que resultasen compatibles con la ordenación urbanística. Para aplicar esta regla, el PGOU tenía que especificar -en el inventario regulado en el artículo 14 del citado Decreto- las parcelas y las edificaciones existentes en cada asentamiento urbanístico, con indicación de sus características básicas. Además, según el apartado 2 de este artículo, en los asentamientos urbanísticos en los que se llevasen a cabo actuaciones de concentración de

34 Por ejemplo, Córdoba, Chiclana de la Frontera o Carmona se encuentran entre los municipios donde el suelo urbano no consolidado proveniente de asentamientos irregulares resulta más voluminoso que el suelo urbano «formal»; es decir, el conformado por el suelo urbano consolidado más el suelo urbano no consolidado sometido a actuaciones de reforma o renovación.

35 En aplicación de esta nueva Instrucción, los PGOU que detrajeron de sus crecimientos urbanos computables el suelo urbanizable transitorio y contaron con Informe de Incidencia Territorial positivo, estarían en situación de claro incumplimiento en base a estos nuevos criterios. Por ejemplo, el caso del PGOU de El Puerto de Santa María. Apenas tres años y medio después de la evacuación del Informe de Incidencia Territorial, su modelo de ciudad transitó de la idoneidad con los presupuestos del POTA a su flagrante incumplimiento, por causa de esta nueva interpretación. 
edificaciones con la finalidad de liberar terrenos del asentamiento para su incorporación al patrimonio público -al objeto de promover su preservación o protección como suelo no urbanizable- no computaban, para el cálculo del crecimiento superficial, los terrenos clasificados como suelo urbanizable ordenado o sectorizado donde se situasen las nuevas parcelas destinadas a las edificaciones objeto de la concentración.

En relación con el crecimiento poblacional, la Instrucción 1/2013 asumió, íntegramente, los criterios de la Instrucción 1/2007, con lo que volvían a computar las viviendas previstas en todas las actuaciones del suelo urbano no consolidado y del suelo urbanizable, procediesen o no del planeamiento objeto de revisión. Solo se podían descontar las viviendas construidas y terminadas, entre las que se encontraban las existentes en asentamientos urbanísticos que resultasen integrables en el modelo territorial establecido en el PGOU. Esta condición de materialidad exigida a la vivienda para ser detraída, también resultaba aplicable en el suelo urbanizable ordenado en ejecución. El cambio de criterio impuesto, en relación a los aplicados hasta la fecha en los Informes de Incidencia Territorial, fue radical. Recordemos que la detracción de actuaciones transitorias -permitida en dichos informes- afectaba tanto a su superficie como a su contenido residencial, aun cuando ni siquiera se hubiera iniciado la ejecución de la urbanización. La única excepción a esta regla general admitida por la Instrucción 1/2013, fue la eliminación de las viviendas contempladas en operaciones de relevancia supramunicipal e interés autonómico.

Finalmente, la Instrucción precisó que, para calcular la equivalencia entre viviendas y habitantes, sería de aplicación el parámetro de 2,4 -fijado por la Orden de 29 de septiembre de 2008- en aquellas actuaciones urbanísticas que tuviesen definido su número máximo de viviendas, o bien la regla establecida en la Instrucción 1/2012, para aquellas en las que no se especificase este dato.

\section{La incidencia del Decreto-Ley 5/2012 en la capacidad del planeamiento general para promover nuevos crecimientos urbanísticos.}

Uno de los aspectos más desilusionantes en el urbanismo andaluz de aquel momento fue la constatación de que, transcurridos más de seis años desde la entrada en vigor del POTA, un porcentaje mínimo de los municipios andaluces contaban con su planeamiento general adaptado a sus determinaciones ${ }^{36}$. La mayor parte de las corporaciones locales optaron por adaptar parcialmente a la LOUA -en desarrollo

36 En la Exposición de Motivos del Decreto-Ley 5/2012 se afirma que, de los 62 municipios costeros solo 10 han revisado sus planes para adaptarse al mencionado Plan regional. Y este porcentaje no es superior en el conjunto de Andalucía donde de los 595 municipios con planeamiento solo 68 (11\%) se han aprobado con posterioridad, y están, por tanto, adaptados al Plan de Ordenación del Territorio de Andalucia. 
del contenido regulado en el Decreto 11/2008- sus obsoletos -pero voluminosos y con altos niveles de consumo de suelo- modelos de ciudad con la finalidad de perpetuarlos en el tiempo, a pesar de su evidente inadecuación a los preceptos no solamente del Plan Regional, sino de la propia ley andaluza. La nueva orientación que, en materia de política territorial, asumió el gobierno regional resultante del pacto de izquierdas tuvo en el Decreto-Ley 5/2012, de 27 de noviembre, de medidas urgentes en materia urbanística y para la protección del litoral de Andalucía, una de sus manifestaciones de mayor relevancia.

La entrada en vigor de este Decreto-Ley introdujo, entre otras, una regulación tremendamente punitiva para aquellos municipios cuyo planeamiento general no se encontrase adaptado a las determinaciones del POTA de forma que, en su artículo 3, se estableció un plazo máximo para que formulasen sus revisiones con la finalidad de acomodarse al Plan Regional. Transcurrido dicho plazo, podía ser sustituida la inactividad municipal en esta materia por la Administración Autonómica y se impediría la tramitación de instrumentos de planeamiento de desarrollo (Planes Parciales, fundamentalmente) que promoviesen un crecimiento superior a los límites establecidos en la Norma 45 del POTA.

Por tanto, a partir de la entrada en vigor del Decreto-Ley 5/2012, había que fiscalizar de manera diferenciada el cumplimiento de la Norma 45 del POTA atendiendo a la diversa casuística que presentase el planeamiento general, distinguiendo entre: (a) PGOUs aprobados con anterioridad al POTA y no adaptados a la citada Norma, (b) PGOUs en vigor antes del POTA pero adaptados a la Norma 45 y, los menos, (c) PGOUs aprobados con posterioridad al POTA.

Para los PGOUs anteriores al POTA -cumplidores o no de la Norma 45.4.a-, la Instrucción 1/2013 convino que el crecimiento urbanístico computable estuviese conformado por todas las actuaciones que se encontrasen pendientes de desarrollo en el momento de entrada en vigor del Decreto-Ley. Es decir, tanto los suelos urbanos no consolidados -para el incremento de población- como los suelos urbanizables con delimitación sectorial, para los crecimientos de población y superficie. El establecimiento de un momento temporal explícito al que referir la verificación del crecimiento urbanístico computable, introdujo un matiz innovador al obviar el carácter dinámico de la clasificación del suelo urbanizable, toda vez que un sector que se hubiese desarrollado con posterioridad a la entrada en vigor del Decreto-Ley 5/2012 -adquiriendo, incluso, la condición jurídica de suelo urbano- continuaba contabilizando como «crecimiento pendiente de desarrollo».

Explicitada la regla aplicable para verificar el cumplimiento de la Norma 45.4.a en los PGOUs vigentes con anterioridad al POTA, la Instrucción introdujo una diferencia sustancial entre: (a) aquellos que superaban los límites al crecimiento 
estipulados en dicha disposición, a los que se les impedía aprobar revisiones parciales y modificaciones que propusiesen nuevos crecimientos urbanísticos, ni formular Planes de Sectorización, y (b) los cumplidores de la citada Norma, en los que se admitían innovaciones reclasificatorias -también Planes de Sectorización- siempre que, sumando los nuevos crecimientos propuestos a los pendientes de desarrollo a la entrada en vigor del Decreto-Ley 5/2012, no se superasen los límites impuestos en la Norma 45.4.a del POTA.

Desvincular la configuración del crecimiento urbanístico computable de la dinámica evolutiva seguida por el PGOU a partir del inicio de la vigencia del Decreto-Ley -el 28 de noviembre de 2012-, fue una decisión congruente con el objetivo de coadyuvar a instrumentar la finalidad principal de este texto legislativo; es decir, promover la adaptación plena al POTA del planeamiento general vigente en la región andaluza. Para ello, resultaba esencial impedir la mutación del modelo de crecimiento que se encontraba pendiente de desarrollo en dicha fecha-admitiendo la detracción de los sectores que hubiesen sido objeto de ejecución urbanística- lo cual favorecería tanto el desarrollo completo del suelo urbanizable previsto, como la posibilidad de promover, progresivamente, nuevas clasificaciones de suelo urbanizable mediante modificaciones del PGOU, desincentivando la formulación de su revisión integral.

La rigidez interpretativa para el cómputo de los crecimientos urbanísticos, también afectó al planeamiento general aprobado con posterioridad a la entrada en vigor del POTA. Así, la Instrucción 1/2013 reguló que, en estos PGOUs, las innovaciones que propongan nuevos crecimientos urbanísticos no podrán superar los límites de crecimiento del POTA en los primeros ocho años desde la aprobación del Plan General, sumados los crecimientos que establezca el Plan General y las sucesivas innovaciones y planes de sectorización aprobados con posterioridad a la entrada en vigor del Plan General. Al tiempo, no se podrán aprobar nuevas innovaciones del Plan General una vez que se haya alcanzado los limites de crecimiento del POTA en los primeros ocho años. En estos casos, deberá procederse a la revisión total del Plan General. Como puede deducirse, el carácter dinámico del suelo urbanizable vuelve a quedar cercenado. En estos casos, la fecha de verificación del crecimiento urbanístico computable era la correspondiente a la aprobación definitiva del PGOU.

En base a estas consideraciones y en aplicación de la Regla V.D de la Instrucción $1 / 2013$, la cuantificación del crecimiento urbanístico propuesto en revisiones parciales y en modificaciones del planeamiento general, incluidos Planes de Sectorización, de PGOUs adaptados al POTA -anteriores o posteriores a su entrada en vigor-, se comenzó a regir por los siguientes criterios:

1. El crecimiento pendiente de desarrollo del PGOU vigente, se computaba con las reglas explicitadas en los párrafos precedentes, en función de si se 
encontraba aprobado con anterioridad o posterioridad a la entrada en vigor del POTA.

2. Al volumen de crecimiento anterior, se tenía que adicionar el previsto en innovaciones, y/o Planes de Sectorización aprobados antes de vencer los ocho años de programación, aun cuando hubiesen sido objeto de ejecución urbanística adquiriendo la condición jurídica de suelo urbano.

3. A los crecimientos computables explicitados en los puntos precedentes, se añadía el propuesto en la nueva innovación, y de la suma total no podía resultar un crecimiento urbanístico que superase los límites de la Norma 45 del POTA.

4. La Disposición transitoria segunda de la Ley 2/2012 estableció que hasta que los Planes Generales de Ordenación Urbanistica se adapten a esta Ley, toda modificación de planeamiento que tenga por objeto un aumento o disminución de la densidad de menos del veinte por ciento no conllevará la alteración de la ordenación estructural de dicho Plan General. Pues bien, la Instrucción 1/2013 determinó que el crecimiento poblacional causado por este incremento de densidad, también tenía que ser contabilizado.

Las conclusiones a extraer de las reflexiones explicitadas en este apartado son concluyentes: la Instrucción 1/2013 supuso un cambio radical en los criterios de evaluación sobre la adaptabilidad de los PGOUS al POTA, demostrativo de la nueva actitud desplegada por el gobierno regional orientada a reconducir la situación existente en el urbanismo andaluz, caracterizado por el desajuste generalizado del planeamiento urbanístico vigente a los principios regulados tanto en el Plan Regional como en la LOUA.

Lo más paradójico de las consecuencias provocadas por la formulación de esta nueva Instrucción es que una parte sustantiva del planeamiento general evaluado con las tesis dominantes durante la vigencia de la Instrucción 1/2007, no cumpliría la regulación de la Norma 45 del POTA. Así, la inadaptación referida en el párrafo anterior no solamente recaía en la mayor parte de los planes aprobados con anterioridad al POTA, sino que se prolongaba en buena parte de los PGOUs formulados con posterioridad al mismo. Lo único que había mediado en ese tránsito del cumplimiento a la inobservancia, fue un cambio de criterio de la Administración Autonómica formalizado en un instrumento -la Instrucción 1/2013- formulado con el exclusivo objeto de dirigir la actividad de los órganos técnicos de la Consejería competente en materia de ordenación del territorio, para elaborar los informes que evaluaban la incidencia territorial de las innovaciones de planeamiento general -revisiones integrales y parciales, modificaciones reclasificatorias, Planes de Ordenación Intermunicipal y Planes de Sectorización- aprobadas inicialmente. 


\section{LA INVOLUGIÓN CAUSADA POR LA INSTRUCGIÓN 1/2014: LA IRRUPGIÓN TRIUNFANTE DE LA HERENGIA URBANÍSTICA RECIBIDA.}

Apenas un año después de la formulación de la Instrucción 1/2013, la Administración Autonómica procedió a su modificación sustancial mediante un nueva Instrucción, la 1/2014 de 7 de Julio que, a día de hoy, continua vigente. Seguramente no es casual que este cambio fuese coetáneo con la situación de inestabilidad política vivida en la Comunidad Andaluza, provocada por las declaradas desavenencias entre los socios del gobierno de coalición de aquel momento, que concluyó con la ruptura del pacto a finales del año 2014 y la convocatoria de nuevas elecciones en enero de 2015. Lo cierto es que, con las tesis interpretativas establecidas en la nueva Instrucción, se produjo un viraje, una vuelta atrás evidente en los rigurosos planteamientos expresados en la anterior Instrucción y, en cierto modo, se desanda el camino hacia la sensatez en materia de urbanismo y ordenación del territorio, emprendido con aquella.

Se ha constatado que el Decreto-Ley 5/2012 reclamaba un cambio de paradigma en el urbanismo andaluz sustentado en los principios de ordenación establecidos en el POTA y la LOUA y que, para ello, era imprescindible atacar los modelos territoriales del planeamiento urbanístico vigente, promoviendo su reconducción por la vía de su revisión total o, caso contrario, ocasionar su «parálisis» adoptando un conjunto de reglas que impidiesen nuevas reclasificaciones de suelo y dificultasen el desarrollo del suelo urbanizable clasificado. Según se ha expuesto en el apartado anterior, transcurridos seis años desde su entrada en vigor, apenas el 11\% de los municipios andaluces contaban con planeamiento general adaptado al POTA, por lo que la regulación del artículo 3 del Decreto Ley 5/2012 afectaba a casi el 90\% de aquellos. La Instrucción 1/2013 se postuló como un instrumento clave para impulsar la metamorfosis requerida, transformando las reglas imperantes para medir la incidencia territorial de las innovaciones del planeamiento general, al objeto de adaptarlas al espíritu de dicho Decreto-Ley y de la Norma 45 del Plan Regional.

Con la nueva Instrucción 1/2014, en gran medida, vuelven a aflorar los criterios aplicados en los Informes de Incidencia Territorial elaborados durante la vigencia de la Instrucción 1/2007 de tal manera que, muchos de los PGOU que se consideraron adaptados al POTA en aquella época y que, caso de evaluarse con la Instrucción 1/2013, hubiesen sido declarados incumplidores de la Norma 45, vuelven a la senda de la adaptabilidad con la aplicación de la nueva Instrucción. Y todo ello, insisto, en el plazo de un año.

En su Introducción, la Instrucción 1/2014 expresa que tiene como objeto establecer criterios, orientaciones y aclaraciones para los distintos órganos de la Administración de la Junta 
de Andalucía con competencia en las materias de ordenación del territorio y urbanismo en relación a la incidencia territorial de los instrumentos de planeamiento urbanístico y la adecuación de sus determinaciones al planeamiento territorial, así como el análisis y valoración de estas cuestiones en los informes que han de emitir estos órganos durante la tramitación y aprobación de dichos instrumentos (...) En su elaboración se ha tenido en cuenta la jurisprudencia habida en estos años en relación con la intervención de la Comunidad Autónoma en el análisis y control del planeamiento urbanístico municipal, su adecuación a la planificación territorial y su posible incidencia territorial y, específicamente, las sentencias del TSFA que resuelven diversos recursos planteados contra el Decreto 206/2006, de 28 de noviembre, por el que se adapta el POTA (STSFA 5119/2010, 5120/2010, y 5155/2010, entre otras) $)^{37}$.

La Instrucción se estructura en tres Capítulos. En su Capítulo I elabora los criterios para comprobar la adaptación del planeamiento urbanístico al POTA. El Capítulo II aborda las reglas para la elaboración, estructura y tramitación de los Informes de Incidencia Territorial y, finalmente, el Capítulo III avanza las reglas a seguir para el cómputo de los crecimientos urbanísticos establecidos por el planeamiento urbanístico general.

En congruencia con el objetivo de este artículo, el análisis del contenido de la Instrucción 1/2014 se centrará en los Capítulos I y III, donde se aborda la regulación de cuestiones determinantes para poder evaluar, tanto la capacidad de innovación que presentan los PGOU no adaptados al POTA, como la estrategia adoptada para computar los nuevos crecimientos -tanto superficiales como poblacionales- propuestos en innovaciones del planeamiento general y que, a la postre, suponen una clara involución en relación con los criterios arbitrados en la anterior Instrucción, encaminados a imponer un cierto orden, control, mesura y proporcionalidad en esta materia.

\section{Criterios para comprobar la adecuación del PGOU a la planificación territorial.}

En el Capítulo I, se establecen los criterios para comprobar la adecuación del planeamiento urbanístico general a los planes de ordenación del territorio y, especialmente, para los procesos de

37 Por ejemplo, la Sentencia del TSJA 5119/2010 de 23 de diciembre, en su Fundamento Jurídico Cuarto, afirma que en cuanto a la planificación territorial, aunque la jurisprudencia no ha sido demasiado explícita al resaltar su naturaleza normativa, ésta se extrae sin esfuerzo de su superioridad jerárquica que legalmente se proclama desde hace tiempo respecto de los planes directores territoriales de coordinación, introducidos por la Ley 19/1975, de 2 de mayo, de reforma de la Ley del Suelo de 1956, y a cuyas determinaciones debian someterse los Planes Generales de Ordenación Urbana (artículos 10.2 del Texto Refundido de la Ley del Suelo, aprobado por Real Decreto Legislativo 1346/1976, de 9 de abril, y 69.2 y 70.2 del Texto Refundido de la Ley del Suelo aprobado por Real Decreto Legislativo 1/1992, de 26 de junio). Por lo mismo, la vinculatoriedad de los actuales planes de ordenación del territorio sobre los planes urbanísticos sólo puede significar que aquellos participan también de la naturaleza normativa de estos». 
adaptación de los PGOU al POTA conforme se establece en el artículo 3 del Decreto Ley 5/2012, de 27 de Noviembre.

Recordemos que, para el caso de PGOUs en vigor con anterioridad al POTA -cumplidores o no de la Norma 45 del POTA- el Decreto-Ley 5/2012 obligaba a su revisión integral una vez superado el plazo máximo de vigencia estipulado su normativa o, caso de no estar fijado, a los 8 años desde su aprobación definitiva. Hasta tanto venza este plazo, estos planes pueden tramitar ordinariamente instrumentos de planeamiento que desarrollen actuaciones urbanísticas -del suelo urbano no consolidado y suelo urbanizable sectorizado- previstas en ellos y -solo para aquellos cumplidores con la Norma 45.4.a del POTA- formular innovaciones reclasificatorias y Planes de Sectorización, posibilidad que estaba cercenada -según la Instrucción 1/2013 - para los planes incumplidores con dicha Norma a la entrada en vigor del Decreto-Ley.

Pues bien, sorprendentemente, la Instrucción 1/2014 habilita a los municipios cuyo planeamiento general se encuentra en esta situación de incumplimiento, a tramitar innovaciones de planeamiento y Planes de Sectorización siempre que los crecimientos urbanísticos que se propongan en éstos, sumados a los de aquellos pendientes de desarrollo, no superen los límites de la Norma 45, conforme a las reglas establecidas en esta Instrucción para el cómputo de dichos crecimientos.

La pregunta a realizarse es: ¿cómo un municipio cuyo PGOU presenta un crecimiento pendiente de desarrollo que, a la entrada en vigor del Decreto Ley 5/2012, supera los límites del POTA, puede promover innovaciones que comporten nuevos crecimientos? La respuesta está, precisamente, en la nueva acepción del «crecimiento pendiente de desarrollo» que introduce la Instrucción 1/2014, desvinculándolo de la fecha de entrada en vigor del Decreto-Ley como plazo temporal de referencia para comprobar tal situación. Con ello, un PGOU anterior al POTA que, en dicha fecha, superase los límites al crecimiento, abandonaría la situación de incumplimiento en el momento que desarrollase un volumen de crecimiento urbanístico suficiente para situarse por debajo de los porcentajes fijados en la Norma 45. Esta «evolución», como se ha visto en el apartado anterior, no era posible en aplicación de la Instrucción $1 / 2013$.

Este cambio, ya de por sí sustancial, se torna revolucionario cuando, para la Instrucción 1/2014, un suelo urbanizable sectorizado deja de estar pendiente de desarrollo si se encuentra en «situación legal y real de ejecución» por contar con su ordenación detallada aprobada definitivamente y aprobado e inscrito registralmente el proyecto de reparcelación. Es decir, sin haber iniciado siquiera las obras de urbanización, el suelo urbanizable -para esta Instrucción- no computa como crecimiento -ni superficial ni, lo más sorprendente, poblacional- si se encuentra ordenado en 
detalle y equidistribuido. La divergencia con los criterios regulados en la Instrucción 1/2013 es más que evidente y, ciertamente, no parece anudarse en cumplimiento alguno derivado del pronunciamiento de los tribunales de justicia. Con esta medida, se facilita que modelos inadaptados a las normas, directrices y recomendaciones del POTA, puedan seguir alimentando la maquinaria de la clasificación de suelo mientras se encuentren dentro de los plazos arbitrados por el Decreto-Ley 5/2012 para proceder a su revisión, lo que proporciona un argumento incuestionable para postergar al máximo su adaptación plena tanto al POTA como a la LOUA.

Sin embargo, las repercusiones de esta nueva concepción de «crecimiento pendiente de desarrollo» son mucho más preocupantes, al subvertir la condición punitiva regulada en el apartado 2 del artículo 3 del Decreto Ley 5/2012 donde, recordemos, se establecía que los planes inadaptados al POTA, una vez superado el plazo para proceder a la revisión, solo podían tramitar instrumentos de planeamiento de desarrollo, siempre que no comportasen crecimientos superiores a los límites de la Norma 45.4.a.

La Instrucción 1/2014 desnaturaliza el espíritu de esta disposición al permitir que un PGOU anterior al POTA e incumplidor de la Norma 45.4.a pueda seguir manteniendo activo el desarrollo de los crecimientos urbanísticos pendientes hasta, incluso, colmatarlos. Efectivamente, según ha quedado explicitado párrafos atrás, promoviendo -antes del vencimiento del plazo establecido para proceder a su revisión- la culminación de la «fase documental» de sectores de suelo urbanizable se consigue su detracción del crecimiento computable con lo que se podría evolucionar a una situación de cumplimiento de la Norma 45.4.a, llegada la cual sería factible, incluso, promover innovaciones con carácter reclasificatorio. Pero, sin duda, lo más paradójico y contradictorio es que, una vez se produzca el vencimiento -pese a la obligación de revisar el PGOU para adaptarse al POTA-, se pueda proseguir desarrollando el resto del suelo urbanizable pendiente, sin peligro de incumplir la Norma 45.4.a, al ir descontando del crecimiento contabilizable todo sector que vaya alcanzando la «situación legal y real de ejecución» ${ }^{38}$.

38 Es decir, un Plan General anterior al POTA que, a la entrada en vigor del Decreto Ley 5/2012, no cumpla, por superarlos, con los límites al crecimiento de la Norma 45.4.a puede tramitar el Plan Parcial de un sector de suelo urbanizable cuyo contenido residencial, pongamos por caso, representa el $30 \%$ de la población existente en el municipio. En el momento que este desarrollo urbanístico haya concluido su fase documental (Plan Parcial y Proyecto de Urbanización aprobados definitivamente más Proyecto de Reparcelación aprobado e inscrito en el Registro de la Propiedad) deja de estar "pendiente de ejecución" y, por tanto, queda detraído del cómputo del crecimiento, por lo que nada impide que el municipio en cuestión pueda promover la tramitación de un nuevo planeamiento de desarrollo que podría alcanzar otro 30\% de crecimiento poblacional. Y así, hasta conseguir el desarrollo de la totalidad del suelo clasificado como urbanizable en el PGOU en cuestión. 
La perpetuación de los modelos de ciudad establecidos en estos PGOUs inadaptados al POTA quedaba garantizada y, ante la obligación de formular -más tarde que temprano- su revisión integral, el volumen de suelo urbanizable computable será testimonial e irrelevante, lo cual activará la pulsión reclasificatoria sin la hipoteca de atender a la herencia urbanística recibida, que se ha invisibilizado a efectos de verificar el cumplimiento del modelo de ciudad preceptuado en el Plan Regional.

Finalmente, para la Instrucción 1/2014, las actuaciones del suelo urbano no consolidado -que si bien no computaban como crecimiento superficial si lo hacían en el apartado de crecimiento poblacional para la Instrucción anterior- dejan de ser computables en su totalidad.

\section{Criterios para evaluar el cómputo del crecimiento urbanístico propuesto en innovaciones del PGOU.}

El Capítulo III de la Instrucción 1/2014 se destina a establecer las reglas aplicables en los Informes de Incidencia Territorial, para evaluar el cómputo de los crecimientos urbanísticos establecidos en innovaciones del planeamiento general. A continuación, se analizarán los aspectos donde esta nueva Instrucción introduce modificaciones sustantivas en relación a la establecida en la Instrucción 1/2013.

En primer lugar, aun cuando la Instrucción 1/2014 certifica la obligación documental del PGOU de justificar la dimensión del crecimiento urbanístico propuesto en base a las dinámicas tendenciales observadas en el municipio en la última década, abre la posibilidad -apartado 1.G) del Capítulo III- de introducir aquellos factores correctores que puedan incidir en el dimensionado, tales como la situación del mercado inmobiliario, la complejidad del sistema de asentamientos del municipio, las previsiones de la política de vivienda y demás circunstancias que afecten al municipio o al área territorial en la que se inserta. De esta forma, el planeamiento podrá adoptar crecimientos urbanísticos superiores a los que se deduzcan de estas dinámicas. Con esta interpretación la Instrucción trataba de hacerse eco de la «no infranqueabilidad» de los límites de la Norma 45 dictaminada en la Sentencia 3894/2011 de 14 de noviembre del TSJA, admitiendo su superación ${ }^{39}$.

39 En esta Sentencia, el Tribunal afirma - en su Fundamento Jurídico Cuarto- que el POTA no establece una prohibición sino un criterio general que debe respetarse salvo justificación razonable y puntual a través de la participación municipal en la elaboración del planeamiento subregional y el planeamiento urbanístico. Derecho de participación en el planeamiento que se configura, como hemos visto en la reseña de la doctrina del Tribunal Constitucional, como el núcleo duro de la defensa de la autonomía local en el ámbito de la planificación urbanística y territorial. $Y$ que se puede materializar, de forma adecuada según la normativa europea traspuesta al derecho español, en la evaluación estratégica de la acción de planificación escogida. Evaluación estratégica territorial de la planificación urbanística que, en su caso, servirá de justificación para proponer crecimientos que superen los contemplados en el artículo 45 de la norma infringida. Pues como hemos visto, las limitaciones reales al crecimiento se encontrarán en la falta de justificación de las excepciones contempladas, así como en la falta de acreditación de la disponibilidad y suficiencia los recursos territoriales y ambientales necesarios para respaldar de crecimiento propuesto por el municipio. 
Otra novedad importante es la referencia que se hace -apartado 1.B) b) del Capítulo III- a que el dimensionado no podrá sobrepasar las necesidades de crecimiento del municipio a medio plazo, en los términos señalados en el artículo 8.1 de la LOUA ${ }^{40}$. Esta regla permite que los PGOUs amplíen su programación temporal. Con ello, la Instrucción asume los requerimientos de una parte importante de la disciplina urbanística que entendía como un encorsetamiento excesivo, y sin aval legal, la reclusión del periodo programable a dos etapas cuatrienales. Esta importante innovación, exige que la medición del crecimiento urbanístico propuesto en el PGOU se realice, de manera independiente, para cada tramo bicuatrienal. Así, en el apartado 3.A) de este Capítulo se establece que, a efectos del cómputo del crecimiento urbanistico, se dividirá el plazo de vigencia del Plan General en periodos sucesivos de ocho años desde su aprobación definitiva. En cada uno de estos periodos se comprobará el cumplimiento de los parámetros de crecimiento establecidos en la Norma 45.

El apartado 2 del Capítulo III se destina a regular la fijación de la población de referencia y la superficie del suelo urbano que sirve de base para el cálculo del crecimiento superficial. Sobre estos aspectos, se mantienen íntegramente las reglas establecidas en la Instrucción 1/2013.

Sin embargo, en el apartado 3 de este Capítulo, se introducen novedades absolutamente determinantes para certificar la defunción del cambio del rumbo emprendido por la anterior Instrucción, al modificar las reglas y criterios de medición de las actuaciones del suelo urbano y alterar en profundidad, como hemos visto, la consideración del crecimiento urbanístico computable. Esta nueva interpretación se empeña en ocultar -para verificar el cumplimiento de la Norma 45 del POTA- el máximo de actuaciones heredadas del planeamiento general objeto de revisión, otorgando al régimen transitorio una condición de «existencia material» similar a la que posee la realidad física tangible, de muy difícil justificación. Las dos medidas innovadoras introducidas por la Instrucción 1/2014 en esta materia son:

1. Para la medición del crecimiento superficial (apartado 3.B) del Capítulo III), no se computará aquellos ámbitos del suelo urbanizable ordenado que se encuentren en situación legal y real de ejecución, por tener aprobada definitivamente la ordenación detallada y aprobado e inscrito en el registro de la propiedad el correspondiente instrumento de equidistribución de beneficios y cargas. Es decir, todo el suelo urbanizable ordenado y equidistribuido no computa en el apartado del crecimiento superficial o, dicho de otra forma, a pesar de no haber iniciado la ejecución de

40 El artículo 8.1 de la LOUA regula que los Planes Generales de Ordenación Urbanística establecen, en el marco de los Planes de Ordenación del Territorio, la ordenación urbanística en la totalidad del término municipal y organizan la gestión de su ejecución, de acuerdo a las características del municipio y los procesos de ocupación y utilización del suelo actuales y previsibles a medio plazo. 
la urbanización -cuya finalización le otorga la condición jurídica necesaria para ser considerado urbano; es decir, integrado en la malla urbana- el suelo urbanizable en «situación legal y real de ejecución» no es considerado crecimiento urbanístico, aun cuando mantenga la situación básica rural regulada en la legislación estata $\left.\right|^{41}$.

A partir de la Instrucción 1/2014 se oficializa la interpretación que, de manera individualizada, metamórfica por casos, cambiante en otros, errática e incierta en todos, estuvieron realizando los Informes de Incidencia Territorial entre 2007 y 2013 otorgando, a efectos de cómputo, a la «ciudad expectante» el carácter físicamente verificable de la «ciudad existente».

Esta decisión, además, acarrea consecuencias importantes en la formulación de revisiones integrales de PGOUs ya que confiere, en la práctica, el carácter de intocables a estos desarrollos urbanísticos heredados del planeamiento general anterior pese a que, en muchas ocasiones, presentan una parametrización urbanística inadecuada para la consecución del modelo de ciudad preceptuado en la planificación territorial y la legislación urbanística. Así, la decisión de detraer estas actuaciones del crecimiento computable para verificar el cumplimiento a la Norma 45 del POTA ha evitado -y lo continúa haciendo en la actualidad- su reordenación urbanística al objeto de que sean reconducidas hacia indicadores expresivos de atributos de sostenibilidad urbana. ¿Qué municipio va a apostar por redefinir estas actuaciones -lo cual comportará la invalidación de su ordenación detallada y, por tanto, la necesidad de una nueva reparcelación- que, de esta manera, dejarían de estar en «situación legal y real de ejecución» volviendo a contabilizar como crecimiento urbanístico? Obvia responder a este interrogante.

Además del triunfante retorno de la «transitoriedad urbanística», se mantienen las excepciones contempladas en la Instrucción 1/2013 para el cómputo del crecimiento superficial: (a) el suelo soporte de las edificaciones consolidadas en los asentamientos irregulares clasificados como suelo urbanizable, (b) las Áreas de Oportunidad de la planificación subregional, (c) las Declaraciones de Interés Autonómico y (d) los campos de golf de interés turístico.

Esta nueva regla de contabilización del incremento superficial es de aplicación tanto en revisiones totales del planeamiento general como en

41 Según el Artículo 21 del TRLSRU, está en la situación de suelo rural, el suelo para el que los instrumentos de ordenación territorial y urbanística prevean o permitan su paso a la situación de suelo urbanizado, hasta que termine la correspondiente actuación de urbanización. 
revisiones parciales, modificaciones y/o Planes de Sectorización que se pretendan formular.

2. En el apartado 3.C) del Capítulo III, la Instrucción 1/2014 aporta las reglas a aplicar para evaluar el crecimiento poblacional, introduciendo dos medidas de gran trascendencia. La primera se centra en la ciudad existente y determina que no se consideran crecimiento poblacional las viviendas previstas en ámbitos del suelo urbano (consolidado o no consolidado), dado el carácter reglado de esta clase de suelo, y en aplicación del artículo 21.2 de la Ley de Ordenación del Territorio de Andalucía, según la cual las Normas del planeamiento territorial sólo son determinaciones de aplicación directa vinculantes en los suelos urbanizables y no urbanizables. Sobre esta decisión, cabe puntualizar dos cuestiones.

En primer lugar, la condición reglada del suelo urbano, definida en el artículo 45 de la LOUA, no ha de quedar desnaturalizada por el hecho de considerar computable el incremento poblacional previsto en las actuaciones -de reforma, renovación, dotación o regularización- del suelo urbano no consolidado. Resulta incomprensible la argumentación empleada en la Instrucción, al parecer fundamentarse en que, al contabilizar -como crecimiento poblacional- el contenido residencial de esta categoría del suelo urbano, se estaría cuestionando su clasificación urbanística.

El suelo que cumple con las condiciones objetivas para ser clasificado como urbano -carácter reglado al que se refiere la Instrucción- puede, en desarrollo de la discrecionalidad otorgada a la capacidad planificadora de la administración, ser categorizado como «no consolidado» por quedar incorporado en una actuación urbanística que, independientemente de su objeto -reforma, renovación, regularización o incremento de aprovechamiento-, promueva una alteración cualificada de la situación preexistente, entre cuyas finalidades se puede encontrar promover incrementos de población vinculados a estrategias de densificación, en cuyo caso deberían ser computables. Además, el régimen jurídico del suelo urbano no consolidado comporta un conjunto de derechos y deberes urbanísticos a los propietarios afectados, similar al del suelo urbanizable sectorizado. Es decir, a estos efectos, el suelo urbano no consolidado se encuentra más próximo al suelo urbanizable que a la categoría de suelo urbano consolidado. Por lo tanto, la decisión de la Instrucción 1/2014 en esta materia hubiese precisado, cuanto menos, de un despliegue argumentativo y justificativo mucho más amplio que la simple referencia al carácter reglado de la clasificación del suelo urbano. 
En segundo lugar, sobre la «no vinculatoriedad» de la planificación territorial a la ordenación del suelo urbano a establecer en los PGOU, recordar el carácter «no atentatorio» de la Norma 45 del POTA a la autonomía local en materia de planificación urbanística, certificado por la jurisprudencia. En concreto, viene a colación, la Sentencia 5119/2010 de 23 de diciembre del TSJA donde, en su Fundamento Jurídico $4^{\circ}$, habilita al POTA a establecer normas de alcance adjetivo (no sustantivo) o formal que no sirvan para ordenar el suelo urbano $^{42}$. Es decir, el Tribunal otorga al POTA, complementariamente a lo regulado en el artículo 21.2 de la LOTA, la potestad de establecer normas que alcancen al suelo urbano siempre que no condicionen la capacidad ordenadora de los PGOU. Puede interpretarse que la Norma 45 del POTA se encuentra en este supuesto, porque no predetermina la ordenación a instrumentar por la planificación urbanística en esta clase de suelo. Es decir, esta disposición no impone cómo intervenir en el suelo urbano, ni determina en qué ámbitos plantear operaciones de transformación urbanística, ni condiciona las directrices que han de orientar su ordenación detallada. La discrecionalidad atribuible al PGOU está garantizada para poder desplegar las estrategias -que considere oportunas- de mejora y recualificación a contemplar en la ciudad existente. El hecho de que el contenido residencial de las actuaciones del suelo urbano no consolidado se considere incremento poblacional, no puede ser el argumento que justifique el incumplimiento del artículo 21.2 de la LOTA, en virtud de lo fundamentado en esta Sentencia.

La interpretación establecida por la Instrucción 1/2014 -en relación con esta facultad de la planificación territorial- cabe considerarla errónea y, además, no es acorde con el objetivo principal de la Norma 45. Efectivamente, al eximir del cómputo todas las viviendas previstas en el suelo urbano -consolidado y no consolidado- se está fomentando un mayor consumo de suelo al incitar que la totalidad del crecimiento poblacional permitido se localice en el suelo urbanizable con delimitación sectorial, incidiendo, más que en la compacidad, en la dispersión territorial del modelo de ciudad.

En cualquier caso, es incuestionable que, a partir de la entrada en vigor de esta Instrucción, todas las actuaciones urbanísticas propuestas en el suelo urbano

42 Esta Sentencia, en su Fundamento Jurídico Cuarto, afirma que las normas de los Planes de Ordenación del Territorio son determinaciones de aplicación directa vinculantes para las Administraciones Públicas y para los particulares, en los suelos urbanizables y no urbanizables (artículo 21.2 Ley 1/1994), previsión cuya evidente finalidad es la de limitar la intervención sustantiva del planeamiento territorial en el suelo urbano, reservando alli naturalmente una mayor intensidad a la ordenación urbanística, aunque lo cierto es que también para este suelo el Plan de Ordenación del Territorio puede establecer normas de alcance adjetivo o formal, como, por ejemplo, las que definen la propia naturaleza del Plan (apartado 1) o la gestión de la política territorial (apartado 7), que se refieren a todo el territorio andaluz, incluido el suelo urbano, pero que, en realidad, no sirven para ordenarlo ni, por lo tanto, desconocen la finalidad de aquella previsión legislativa. 
no consolidado quedan excluidas del incremento poblacional cuantificable a efectos de constatar el cumplimiento de la Norma 45.4.a del POTA. Y digo bien: todas. Es decir, no sólo las actuaciones transitorias -como había sido interpretado en la mayor parte de Informes de Incidencia Territorial evacuados con la Instrucción 1/2007- sino también las propuestas «ex novo» por la revisión del PGOU. Esta regla modifica radicalmente la establecida en la Instrucción 1/2013, donde todas las viviendas del suelo urbano no consolidado que no se encontrasen materializadas, debían integrarse en la configuración del crecimiento poblacional propuesto.

La recepción, por parte de Ayuntamientos, propietarios de suelo y sector promotor-inmobiliario, de esta medida fue de aceptación total, al adecuarse plenamente a sus requerimientos, orientados a garantizar la mayor capacidad posible de crecimiento urbanístico mediante nuevas clasificaciones de suelo urbanizable ${ }^{43}$.

La segunda de las cuestiones a la que me refería anteriormente, afecta a los suelos urbanizables ordenados en «situación legal y real de ejecución». Pues bien, la Instrucción 1/2014, como ya ha quedado apuntado, no solamente elimina del cómputo superficial esta categoría de suelo urbanizable transitorio, sino que, en un alarde interpretativo claramente posicionado con las posiciones adscritas al urbanismo neoliberal, establece, en el apartado 3.C) 2.a) del Capítulo III, que no se computará para el crecimiento poblacional aquellos ámbitos del suelo urbanizable ordenado que se encuentren en situación legal y real de ejecución, por tener aprobada definitivamente la ordenación detallada y aprobado e inscrito en el registro de la propiedad el correspondiente instrumento de equidistribución de beneficios y cargas. Es decir, el suelo urbanizable que haya alcanzado esta situación procedimental se diluye, se volatiliza, se torna invisible a efectos de verificar el cumplimiento de la Norma 45 del POTA ${ }^{44}$. Con esta medida, la

43 La Junta abre el corsé y flexibiliza los límites de crecimiento a los municipios. Ordenación del Territorio reinterpretará el artículo 45 del POTA para no "lastrar" nuevas oportunidades de desarrollo urbanístico El objetivo es reactivar el sector de la construcción. La Junta de Andalucía sigue añadiendo ingredientes a la fórmula con la que reactivar el sector de la construcción en la región. La Consejería de Medio Ambiente y Ordenación del Territorio tiene previsto presentar esta semana una instrucción mediante la que "flexibilizar" la forma de interpretar los límites de crecimiento contenidos en el Plan de Ordenación Territorial de Andalucía (POTA), que impide a los municipios ir más allá del 30\% de aumento de población y del $40 \%$ en lo que a ocupación de suelo refiere. Ello, de facto, supone abrir la mano al férreo corsé al que, en apariencia, han estado sometidos los municipios desde que entrase en vigor esta herramienta. Noticia de prensa aparecida en el Diario de Sevilla el 6 de julio de 2014.

44 En la unidad territorial de la Costa del Sol Occidental se encuentran en "situación legal y real de ejecución" un total de 2.784,8 hectáreas de suelo urbanizable -el 65,68\% del total- con un contenido residencial de 47.927 viviendas que, en base a la Instrucción 1/2014, no computarían como crecimiento poblacional. Esta cifra representa un techo poblacional aproximado de 165.793 habitantes, el $41,86 \%$ de 
Instrucción 1/2014 termina por certificar la extinción de su antecesora que, dado su corto periodo de vida, puede considerarse prácticamente nonata. La Instrucción 1/2013 fue un espejismo en el «desierto neoliberalizador», hábitat natural definitorio de la política territorial desplegada, en estos años, en la Comunidad Andaluza.

Finalmente, indicar que la Instrucción 1/2014 mantiene la exención de las actuaciones estratégicas contempladas en la planificación subregional, de las actuaciones de interés autonómico y los campos de golf de interés turístico.

Las consecuencias de esta nueva Instrucción son fácilmente previsibles para nuevas revisiones de PGOUs. Sin embargo, nadie reparó en el agravio que ha ocasionado en planes -como el de Alcalá de Guadaira antes expuesto- que fueron declarados incumplidores de la Norma 45 en la época disléxica que abarca desde 2007 a 2013. Estos PGOUs -alguno de los cuales no se han repuesto aún del impacto denegatorio-, tan sólo unos pocos años después, hubiesen tenido una incidencia territorial positiva en aplicación de la Instrucción 1/2014.

\section{GONCLUSIONES.}

El urbanismo de la burbuja inmobiliaria gestada durante la denominada "década prodigiosa" (1997-2007), se ha caracterizado por la incentivación de un expansivo proceso de artificialización territorial cimentado en la sobreclasificación de suelo urbanizable, demiurgo urbanístico que ha principiado la práctica totalidad de las decisiones de planificación en este periodo ${ }^{45}$. La principal consecuencia de esta estrategia ha sido la configuración de unos modelos territoriales dispersos que -en el caso de la región andaluza- incumplen los principios de sostenibilidad urbana impregnados en los preceptos de la legislación urbanística (LOUA) y desarrollados con exhaustividad en el Plan de Ordenación del Territorio de Andalucía (POTA). Ante esta preocupante situación, parece existir un consenso generalizado en la disciplina urbanística sobre la solución a ensayar, que debe apoyarse en «una revisión generalizada del planeamiento para adaptarlo a un horizonte de no crecimiento, de contención urbana, de ajuste a las verdaderas necesidades, con una demografía a la baja, y con un parque acumulado de vivienda, que excede de las demandas previsibles en el más expansivo de los escenarios ${ }^{46}{ }$.

la población actual. (Datos extraídos del Documento de Análisis y Diagnóstico Territorial del POT de la Costa del Sol Occidental elaborado por la consultora Territorio y Ciudad SLP).

45 AMAT MONTESINOS, X., "Decrecimiento y renovadas estrategias para un territorio agotado", en Cuadernos Geográficos 54 (2), (2015), pp. 6-37.

46 GAJA I DÍAZ, F., "Reparar los impactos de la burbuja constructora", en Scripta Nova, 517 (2015), p. 22. 
Existen Comunidades Autónomas, que han emprendido esta ruta. En Castilla y León, la disposición tercera de la Ley 7/2014, de 12 de septiembre, de medidas sobre rehabilitación, regeneración y rehabilitación urbana y sobre sostenibilidad, coordinación y simplificación en materia de urbanismo, establece plazos para demostrar la viabilidad de los terrenos clasificados como suelos urbanizables por el planeamiento vigente que, caso de incumplirse, retornarían a su condición previa de suelo rústico común. Por su parte, la Comunidad Valenciana ha incluido, en el Proyecto de Modificación de la Ley de Ordenación del Territorio, Urbanismo y Paisaje -sometido a trámite parlamentario en el momento de escribir estas líneas- un innovador procedimiento denominado "reparcelación inversa" que, en resumen, pretende dejar sin efecto la equidistribución efectuada en desarrollos urbanísticos inconclusos mediante su reversión, con la finalidad de que las fincas resultantes sean las rústicas originales aportadas a dicho proceso. Es decir, se trata de restituir a su condición rural suelos, afectados por la repentina deflagración de la burbuja inmobiliaria, cuyas expectativas urbanísticas fueron concebidas en un periodo caracterizado por la desmesura territorial. Ambas estrategias son expresivas de, podría decirse, «un urbanismo de marcha atrás».

En nuestra Comunidad, sin embargo, a raíz de la entrada en vigor del Plan Regional, se han ido desarrollando -concebidas, diseñadas e instrumentadas por la Administración Autonómica- un conjunto de «contramedidas» orientadas a desvirtuar y desnaturalizar los límites al crecimiento urbano regulados en su Norma 45.4.a, para permitir su sistemática superación. Entre ellas, asume un papel relevante la deriva interpretativa -adoptada a través de la convulsa secuencia de Instrucciones administrativas expuesta en este artículo- de dicha disposición, al objeto de invisibilizar, a efectos de crecimiento computable, determinadas actuaciones urbanísticas: las de uso residencial del suelo urbano no consolidado, el suelo urbanizable en régimen de transitoriedad y aquellas de condición estratégica e incidencia supramunicipal (Áreas de Oportunidad y campos de golf de interés turístico). Especial sorpresa causa la consideración como «no computable»-tanto en términos de crecimiento superficial como poblacional- del suelo urbanizable en «situación legal y real de ejecución» -es decir aquel que se encuentra ordenado en detalle y equidistribuido o reparcelado- otorgando condición de materialidad urbana a unos terrenos en los que ni siquiera han comenzado las obras de urbanización. La diferencia con el trayecto iniciado en las reformas legislativas apuntadas en el párrafo precedente es plausible.

En conclusión, el relato desplegado en este texto ha mostrado un epifenómeno revelador de la política territorial y urbanística adoptada en la región andaluza -durante la travesía de la recesión económica- dirigida a fomentar un «urbanismo reincidente», que debe ser revertida. El proceso abierto con la formulación de un nuevo texto legislativo en materia urbanística que sustituya a la actual LOUA, representa 
una oportunidad para ello, explorando nuevos principios, criterios y directrices que impulsen un urbanismo regenerativo y transformacional que reconduzca -en claves de sostenibilidad- la herencia territorial recibida de los años del frenesí inmobiliario.

\section{INSTRUGCIONES ADMINISTRATIVAS.}

Instrucción 1/2007 de la Secretaría General De Ordenación Del Territorio, sobre la elaboración y tramitación de los informes de incidencia territorial de los planes generales de ordenación urbanística.

Instrucción 1/2012 de la Dirección General de Urbanismo a los órganos urbanísticos de la Consejería de Obras Públicas y Vivienda en relación con la entrada en vigor y aplicación de la ley 2/2012, de 30 de enero, de modificación de la ley 7/2002, de 17 de diciembre, de Ordenación Urbanística de Andalucía.

Instrucción 1/2013 de la Secretaría General de Ordenación del Territorio sobre los criterios que deben adoptarse para la medición del crecimiento urbanístico propuesto por el planeamiento general, conforme a la norma 45.4.a) del Plan de Ordenación del Territorio de Andalucía.

Instrucción 1/2014 de la Secretaría General de Ordenación del Territorio y Cambio Climático en relación a la incidencia territorial de los instrumentos de planeamiento urbanístico general y la adecuación de los mismos a la planificación territorial.

\section{NORMATIVA GITADA.}

Ley 19/1975, de 2 de mayo, de reforma de la Ley sobre Régimen del Suelo y Ordenación Urbana, Boletín Oficial del Estado, 5 de mayo de 1975, 197.

Ley 40/2015, de 1 de octubre, de Régimen Jurídico del Sector Público, Boletín Oficial del Estado, de 2 de octubre de 2015, 236.

Real Decreto Legislativo 7/2015, de 30 de octubre por el que se aprueba el Texto Refundido de la Ley del Suelo y Rehabilitación Urbana. Boletín Oficial del Estado de 31 de octubre de 2015, 261.

Ley 1/1994, de 11 de enero, de Ordenación del Territorio de la Comunidad Autónoma de Andalucía, Boletín Oficial de la Junta de Andalucía, de 22 de enero, 8.

Ley 7/2002 de Ordenación Urbanística de Andalucía (revisión vigente desde el 6 de Agosto de 2016), Boletín Oficial de la Junta de Andalucía, 31 de diciembre de 2002, 154.

Ley 1/2008, de 27 de Noviembre, de medidas tributarias y financieras de impulso a la actividad económica de Andalucía y de agilización de los procedimientos 
administrativos, Boletín Oficial de la Funta de Andalucía, de 11 de diciembre de 2008, 245.

Ley 2/2012 de 30 de enero, de modificación de la Ley 7/2002 de 17 de diciembre de Ordenación Urbanística de Andalucía, Boletín Oficial de la Junta de Andalucía, de 8 de febrero de 2012, 26.

Decreto 206/2006, de 28 de noviembre, por el que se adapta el Plan de Ordenación del Territorio de Andalucía a las Resoluciones aprobadas por el Parlamento de Andalucía en sesión celebrada los días 25 y 26 de octubre de 2006 y se acuerda su publicación, Boletín Oficial de la Junta de Andalucía, 29 de diciembre de 2006, 250.

Decreto 11/2008, de 22 de enero, por el que se desarrollan procedimientos dirigidos a poner suelo urbanizado en el mercado con destino preferente a la construcción de viviendas protegidas, Boletín Oficial de la Junta de Andalucía, 27 de febrero de $2008,27$.

Decreto 43/2008, de 12 de febrero, regulador de las condiciones de implantación y funcionamiento de campos de golf en Andalucía. Boletín Oficial de la funta de Andalucía, de 27 de febrero de 2008, 41.

Decreto 309/2010, de 15 de junio, por el que se modifica el Decreto 43/2008. Boletín Oficial de la Junta de Andalucía, 18 de junio de 2010, 119.

Decreto 2/2012, de 10 de enero, por el que se regula el régimen de las edificaciones y asentamientos existentes en suelo no urbanizable en la Comunidad Autónoma de Andalucía, Boletín Oficial de la Junta de Andalucía, de 30 de enero de 2012, 19.

Decreto-Ley 5/2012, de 27 de noviembre, de medidas urgentes en materia urbanística y para la protección del litoral de Andalucía. Boletín Oficial de la funta de Andalucía, de 28 de noviembre de 2012, 233.

Orden de 29 de septiembre de 2008, por la que se regula el coeficiente aplicable para el cálculo de crecimiento poblacional derivado de las viviendas previstas en los instrumentos de planeamiento urbanístico, Boletín Oficial de la Junta de Andalucía, 21 de octubre de 2008, 209.

\section{SENTENGIAS JUDIGIALES.}

Sentencia 1129/2016, de 14 de marzo, del Tribunal Supremo. www.poderjudicial.es.

Sentencia 5119/2010, de 23 de diciembre, del Tribunal Superior de Justicia de Andalucía. www.poderjudicial.es. 
Sentencia 3894/2011, de 14 de noviembre, del Tribunal Superior de Justicia de Andalucía. www.poderjudicial.es.

Sentencia 5496/2014, de 5 junio, del Tribunal Superior de Justicia de Andalucía. www.poderjudicial.es 


\section{BIBLIOGRAFÍA.}

AMAT MONTESINOS, Xavier (2015). "Decrecimiento y renovadas estrategias para un territorio agotado". Cuadernos Geográficos, 54 (2), pp. 6-37.

BARRANCO VELA, Rafael (2010). "La problemática jurídica de los campos de golf (II): condiciones ambientales y urbanísticas. Especial referencia al Decreto andaluz de campos de golf". Revista andaluza del derecho del deporte (8), 325-370.

GAJA I DÍAZ, Fernando (2015). "Reparar los impactos de la burbuja constructora" Scripta Nova, 517, pp. 1-37.

GÓRGOLAS MARTÍN, Pedro (2016). La planificación de la ciudad en el cambio de milenio (1997-2017). Propuestas para reconducir la herencia recibida: los casos de Casares (Málaga) y Chiclana de la Frontera (Cádiz). Tesis Doctoral, Departamento de Urbanística y Ordenación del Territorio de la Universidad de Sevilla.

GÓRGOLAS MARTÍN, Pedro (2017a). "La planificación territorial de ámbito subregional en el litoral andaluz: de la «condescendencia» con el planeamiento general en vigor a la «adulteración» del modelo de ciudad regulado en el Plan de Ordenación del Territorio de Andalucía”. Práctica urbanística, 147. Editorial Wolters Kluwer, pp. 1-19.

GÓRGOLAS MARTÍN, Pedro (2017b). "Diez años de vigencia del Plan de Ordenación del Territorio de Andalucía. Luces y sombras de la planificación territorial. La desnaturalización del modelo de ciudad compacta". Revista Andaluza de Administración Pública, 97, pp. 319-350.

GÓRGOLAS MARTÍN, Pedro. "La regulación de los campos de golf en la Comunidad Autónoma de Andalucía: ¿interés turístico o interés inmobiliario? ". Cuadernos Geográficos, 57 (1), pp. 283-304.

MATESANZ PARELLADA, Ángela (2014) "El suelo en la legislación urbanística española." Boletin $C F+S$ 51, pp. 7-60.

OLMEDO PEREZ, Sebastián (2016). "Reflexiones sobre las edificaciones clandestinas en suelo no urbanizable en Andalucía y los intentos de la Comunidad Autónoma de Andalucía para su reconducción”, en: Práctica Urbanística, 139. Editorial Wolters Kluwer, pp 32-61.

SÁNCHEZ GONZÁLEZ, Juan Francisco (2011). "La consideración de las limitaciones al crecimiento como parámetro de sostenibilidad del medio ambiente urbano". Revista Andaluza de Administración Pública, 81, pp. 13-46.

ZAMORANO WISNES, José (2013). "Comentarios al Decreto 5/2012 de medidas urgentes en materia urbanística y para la protección del litoral”. Revista Andaluza de Administración Pública, 85, pp 407-425. 